\title{
Loss of SynDIG1 Reduces Excitatory Synapse Maturation But Not Formation In Vivo
}

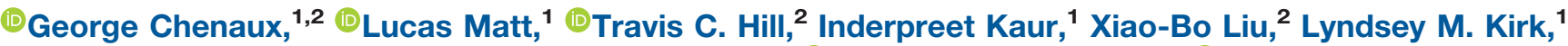 \\ David J. Speca, ${ }^{1}$ Samuel A. McMahon, ${ }^{1}$ Karen Zito, ${ }^{2}{ }^{\circledR}$ Johannes W. Hell, ${ }^{1}$ and ${ }^{\circledR E}$ Elva Díaz ${ }^{1}$
}

DOI:http://dx.doi.org/10.1523/ENEURO.0130-16.2016

${ }^{1}$ Department of Pharmacology, University of California, Davis, California 95616, and ${ }^{2}$ Center for Neuroscience, University of California, Davis, California 95616

\begin{abstract}
Modification of the strength of excitatory synaptic connections is a fundamental mechanism by which neural circuits are refined during development and learning. Synapse Differentiation Induced Gene 1 (SynDIG1) has been shown to play a key role in regulating synaptic strength in vitro. Here, we investigated the role of SynDIG1 in vivo in mice with a disruption of the SynDIG1 gene rather than use an alternate loxP-flanked conditional mutant that we find retains a partial protein product. The gene-trap insertion with a reporter cassette mutant mice shows that the SynDIG1 promoter is active during embryogenesis in the retina with some activity in the brain, and postnatally in the mouse hippocampus, cortex, hindbrain, and spinal cord. Ultrastructural analysis of the hippocampal CA1 region shows a decrease in the average PSD length of synapses and a decrease in the number of synapses with a mature phenotype. Intriguingly, the total synapse number appears to be increased in SynDIG1 mutant mice. Electrophysiological analyses show a decrease in AMPA and NMDA receptor function in SynDIG1-deficient hippocampal neurons. Glutamate stimulation of individual dendritic spines in hippocampal slices from SynDIG1deficient mice reveals increased short-term structural plasticity. Notably, the overall levels of PSD-95 or glutamate receptors enriched in postsynaptic biochemical fractions remain unaltered; however, activity-dependent synapse development is strongly compromised upon the loss of SynDIG1, supporting its importance for excitatory synapse maturation. Together, these data are consistent with a model in which SynDIG1 regulates the maturation of excitatory synapse structure and function in the mouse hippocampus in vivo.
\end{abstract}

Key words: AMPA receptor; excitatory synapse; hippocampus; synapse development; synapse maturation; SynDIG1

\section{Significance Statement}

Synapse Differentiation Induced Gene 1 (SynDIG1) is a brain-specific transmembrane protein that is enriched at excitatory synapses. Removal of endogenous SynDIG1 in the mouse brain results in a significant reduction in excitatory synapse maturation, as determined by a combination of structural and electrophysiological approaches. In contrast, biochemical analysis reveals that excitatory synapse composition is unchanged upon the loss of SynDIG1. Together, these data support a model in which SynDIG1 is important for excitatory synapse maturation but is not required for synaptogenesis in vivo.

\section{Introduction}

The mammalian CNS enables sophisticated computation and behavior due to the development of a stagger-

Received May 21, 2016; accepted September 22, 2016; First published October 05, 2016.

The authors declare no competing financial interests. ingly complex neuronal network (Jessell and Kandel, 1993). This circuitry depends upon precise cell-cell communication, which occurs at the synapse. Glutamate re- 
leased by the presynaptic cell activates NMDA, AMPA, and/or kainate-type ionotropic glutamate receptors. The majority of synapses are formed postnatally (Waites et al., 2005; McAllister, 2007), yet synapses remain plastic and can be formed, lost, strengthened, or weakened throughout adulthood. Functional excitatory synapse maturation is in part dependent on the directed trafficking of AMPA receptors to postsynaptic sites, which has been the topic of intense investigation (Malinow and Malenka, 2002; Bredt and Nicoll, 2003; Chen et al., 2007). Synaptic targeting of AMPA receptors is regulated by intracellular scaffolding proteins (Elias and Nicoll, 2007) as well as by a diverse array of transmembrane accessory proteins (Jackson and Nicoll, 2011; Haering et al., 2014).

Synapse Differentiation Induced Gene I (SynDIG1) was identified in a screen comparing gene expression profiles from the cerebella of wild-type (WT) animals to Lurcher mice, which display defects in Purkinje neuronal differentiation (Díaz et al., 2002). SynDIG1 is a highly conserved type II integral membrane protein with a large intracellular $\mathrm{N}$-terminal region followed by a single transmembrane domain and a second hydrophobic segment that does not span the membrane (Kalashnikova et al., 2010). SynDIG1 overexpression in cultures of dissociated rat hippocampal neurons results in a significant increase in excitatory synapse strength and number, as reflected by increased postsynaptic density (PSD)-95 and AMPA receptors at excitatory synapses while the knockdown of SynDIG1 results in a decrease of synaptic PSD-95 and AMPA receptor levels (Kalashnikova et al., 2010). There is conflicting evidence concerning the regulation of NMDA receptors by SynDIG1. In cultures of dissociated rat hippocampal neurons, NMDA receptor-dependent miniature EPSC (mEPSC) and synaptic NMDA receptor content were unchanged upon SynDIG1 overexpression or knockdown (Kalashnikova et al., 2010), suggesting that SynDIG1 selectively regulates synaptic strength by altering the levels of AMPA receptors and PSD-95 at synapses.

This work was supported by funds provided to E.D. from the National Institutes of Health (NIH) Director's New Innovator Award Program (DP2-OD006479-01), the National Science Foundation (NSF; Grant 1322302), and a Pilot Grant from the University of California, Davis Academic Senate Research Program; by funds provided to J.W.H. from the NIH (Grant R01-NS-078792); by funds provided to K.Z. from the NSF (Grant 0845285); and American Heart Association Postdoctoral Fellowship 11POST7020009, and National Alliance for Research on Schizophrenia and Depression Young Investigator Grant 20748 from the Brain \& Behavior Research Foundation (to L.M.).

L. Matt's present address: Department of Pharmacology, Toxicology and Clinical Pharmacy, Institute of Pharmacy, University of Tübingen, Tübingen, Germany 72074

Acknowledgments: We thank members of the Diaz, Hell, McAllister, Trimmer, and Zito laboratories at the University of California, Davis for valuable input and suggestions throughout this project; D. Guerra and J. Callis for providing the antibody against $\beta$-galactosidase; K. Mitchell for assistance with gene-trap annotation; and $\mathrm{M}$. Pham for help with immunoblotting.

Correspondence should be addressed to Elva Díaz, Department of Pharmacology, UC Davis School of Medicine, 451 Health Sciences Drive, 3503 GBSF, Davis, CA 95616. E-mail: ediaz@ucdavis.edu.

DOI:http://dx.doi.org/10.1523/ENEURO.0130-16.2016

Copyright (C) 2016 Chenaux et al.

This is an open-access article distributed under the terms of the Creative Commons Attribution 4.0 International, which permits unrestricted use, distribution and reproduction in any medium provided that the original work is properly attributed.
However, shRNA targeted to SynDIG1 in hippocampal slice culture resulted in decreased mEPSC frequency, a trend toward decreased mEPSC amplitude and decreased AMPA receptor and NMDA receptor synaptic transmission (Lovero et al., 2013), suggesting a more general role in excitatory synapse development. One explanation for these differences might reflect the efficiency of the knockdown of SynDIG1 in dissociated hippocampal neurons compared with hippocampal slice culture. For example, in hippocampal slice culture, SAP-102 knockdown via biolistic delivery of shRNA reduced both AMPAR and NMDAR currents, while SAP-102 knockdown via viral delivery of shRNA had no effect on AMPAR current and provided a small decrease in NMDAR current (Levy et al., 2015), suggesting that biolistic delivery might be more efficient at knockdown compared with viral delivery.

Given the differences in the ability of SynDIG1 to regulate excitatory synapses and modulate glutamate receptor function in dissociated hippocampal neurons and in slice culture, it is essential to understand when and how SynDIG1 functions during neural development within the intact brain. To rigorously address these issues, we established and characterized SynDIG1 mutant mice. Here we demonstrate that mice with reduced SynDIG1 exhibit deficits in the ultrastructure and function of mature excitatory synapses. The overall reduction in the number of mature synapses by multiple criteria suggests that SynDIG1 is important for development. In contrast, biochemical fractionation studies indicate no significant differences in synapse composition. Together, SynDIG1 appears to play an important role in the ability of excitatory synapses to reach or sustain maturity in vivo without gross changes to normal synapse composition.

\section{Materials and Methods}

\section{Characterization of a conditional SynDIG1 $1^{\text {flox }}$ allele}

All animal procedures followed National Institutes of Health (NIH) guidelines and have been approved by the Institutional Animal Care and Use Committee at the University of California, Davis. Preliminary analyses were performed on a conditional SynDIG1 allele generated by the Mouse Biology Program at the University of California, Davis, referred to here as SynDIG $1^{\text {flox }}$. A targeting vector harboring a neomycin resistance (neo) cassette flanked by FRT sites and loxP sites flanking exon 4 was electroporated into mouse embryonic stem cells. Flp recombinase exposure in vitro excised the neo cassette. Molecular analyses were performed on a mixed C57BL/6N and C57BL/6J genetic background. For RNA analysis, SynDIG1 $1^{\text {flox/+ }}$ heterozygous mice were crossed with a nestin Cre driver line [Tg(Nes-cre)1KIn; RRID:IMSR_JAX:003771] generating heterozygous mice with Nes$\mathrm{cre}^{+}$cells in which exon 4 was deleted (SynDIG1 ${ }^{\Delta e x o n 4 /+}$ ). Subsequent breeding generated homozygous mutant mice (SynDIG1 $1_{\text {exon } 4 / \Delta \text { exon } 4}$ ), heterozygous mutant mice $\left(S y n D I G 1^{\Delta \text { exon } 4 /+}\right)$, and homozygous wild-type mice (Syn$\left.D / G 1^{+/+}\right)$that expressed the Cre transgene. For immunoblot analysis, SynDIG1 $1^{\text {flox/+ }}$ heterozygous mice were crossed with a CMV-cre driver line [B6.C-Tg(CMV-cre) 1Cgn/J; RRID:IMSR_JAX:006054] generating heterozy- 
gous mice with CMV-cre ${ }^{+}$cells in which exon 4 was deleted $\left(S y n D / G 1^{\text {exon } 4 /+}\right)$. Subsequent breeding of heterozygous SynDIG1 ${ }^{\text {Dexon4/+ }}$ mice generated homozygous mutant mice (SynDIG1 $\left.1^{\Delta e x o n 4 / \Delta e x o n 4}\right)$, heterozygous mutant mice (SynDIG $1^{\text {eexon } 4 /+}$ ), and homozygous wildtype mice $\left(S y n D / G 1^{+/+}\right)$that expressed the Cre transgene. In all experiments, SynDIG1 mutant mice were compared with mice with the unmodified wild-type SynDIG1 allele.

\section{Generation of SynDIG1 ${ }^{\beta-g a l}$ mutant mice and subsequent breeding}

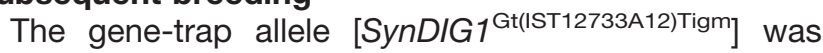
generated by the Texas A\&M Institute for Genomic Medicine (TIGM; RRID:IMSR_TIGM:IST12733A12). The Victr 76 viral plasmid was used to insert a splice acceptor, a $\beta$-geo ( $\beta$-galactosidase/neomycin) cassette, and a synthetic polyA signal/transcriptional blocker all flanked by two viral long-terminal repeat segments in between exons 4 and 5 of the SynDIG1 locus. Mice were housed under IACUC standards and were maintained in the C57BL/6 strain. Embryonic mouse ages are defined as embryonic day 0.5 (E0.5) upon first discovery of a vaginal plug. The day of birth is referred to as postnatal day $0(\mathrm{PO})$. These mice are referred to as SynDIG ${ }^{\beta-\text { gal }}$ mutants.

Splicing to the inserted sequence in the SynDIG1 trapped allele is predicted to generate a transcript that encodes 5 aa (VEEQA) followed by a stop codon immediately after the SynDIG1 transmembrane domain encoded by exon 4 at position 206, thereby resulting in a SynDIG1 mutant protein composed of 211 aa with a calculated molecular weight of $23.6 \mathrm{kDa}$. Immunoblot analysis with anti-SynDIG1 antibody (epitope within amino acids 19-43) does not detect a protein in this size range, suggesting that the mutant SynDIG1 protein is not stably expressed. A fusion protein between SynDIG1 and $\beta$-geo is not predicted based on sequence information. Consistently, immunoblot analysis with antibodies against $\beta$-galactosidase ( $\beta$-gal) recognizes bands at $\sim 150 \mathrm{kDa}$ that are not recognized by the SynDIG1 antibodies. Therefore, $\beta$-gal expression is likely driven by the SynDIG1 promoter, and this reporter protein is mostly retained within the cell body in SynD/G1 ${ }^{\beta-\text { gal }}$ mutants.

\section{Total RNA isolation and RT-PCR}

Total RNA was isolated from adult brain tissue using TRIzol reagent (Invitrogen). Superscript III (ThermoFisher Scientific) was used for first strand synthesis. Subsequent PCR amplification utilized two primers (forward: CAC CAA AGA CAG CCT GGA GT) and (reverse: GGC CTG ATG GAA GTC TCC TT), which annealed to the sequence in exon 3 and exon 5 , respectively, to amplify products of 295 or 138 bp, respectively, in wild-type or SynDIG $1^{\text {dexon } 4}$ transcripts.

\section{Biochemical fractionation and immunoblotting}

For characterization of protein expression in SynDIG $1^{\text {flox }}$ and SynDIG $1^{\beta \text {-gal }}$ animals, brain tissue was homogenized in a dounce homogenizer in $0.32 \mathrm{M}$ sucrose and $1 \mathrm{~mm}$ HEPES, pH 7.4, with protease inhibitors (leupeptin, aprotinin, pepstatin $A$, and phenylmethylsulfonyl fluoride). Lysate was spun for $10 \mathrm{~min}$ at $10,000 \times \mathrm{g}$, and the resultant crude synaptosomal membrane fraction was used for immunoblot analysis, as described below.

For biochemical fractionation, the rostral two-thirds of mouse brains were homogenized in a dounce homogenizer in $0.32 \mathrm{~m}$ sucrose, $1 \mathrm{~mm}$ Tris, $\mathrm{pH} 7.4$, and $1 \mathrm{~mm}$ $\mathrm{MgCl}_{2}$ with protease inhibitors (leupeptin, aprotinin, pepstatin $\mathrm{A}$, and phenylmethylsulfonyl fluoride). Lysate was spun for $15 \mathrm{~min}$ at $1400 \times \mathrm{g}$. Supernatant was collected and saved. The pellet was homogenized with more sucrose solution, and large insoluble debris and the nuclear fraction were removed by centrifugation at $710 \times g$. The supernatants were pooled, and an aliquot was saved as the postnuclear supernatant (S1) fraction. The remaining S1 was centrifuged at $16,000 \times g$, and the pellet was collected as the membrane-enriched fraction (P2), while the supernatant was considered the cytoplasmic proteinenriched supernatant (S2) fraction. The P2 fraction was resuspended in a $0.32 \mathrm{M}$ sucrose solution without $\mathrm{MgCl}_{2}$, and was layered over $0.85,1.0$, and $1.25 \mathrm{M}$ sucrose gradients, spun at $40,000 \times g$ for $2 \mathrm{~h}$, and synaptosomalenriched fraction (Syn) was collected between 1.0/1.25 M gradients. Triton X-100 was added to Syn to a final concentration of $0.5 \%$ and incubated for $15 \mathrm{~min}$ at $4^{\circ} \mathrm{C}$. The pellet was collected after spinning at $100,000 \times g$ for 30 min. An aliquot of the supernatant was saved as a presynaptic fraction containing synaptic vesicle proteins and other presynaptic proteins [synaptic vesicle- and presynaptic-enriched (S3) fraction]. The pellet was resuspended in sucrose buffer, placed over another sucrose gradient (1.0/1.5/2.0 M), centrifuged at 40,000 $\times g$ for $2 \mathrm{~h}$, and the second gradient layer was collected in $1.5 / 2.0 \mathrm{M}$ sucrose. This fraction was exposed to Triton X-100 again, and a final PSD pellet was collected after centrifugation at $100,000 \times g$ for $1 \mathrm{~h}$, with the pellet resuspended via sonication to obtain the PSD-enriched fraction (PSD).

Protein levels were quantified using a BCA assay (ThermoScientific Pierce). The $10-20 \mu \mathrm{g}$ of each biochemical fraction was separated on SDS-PAGE gels ranging from $7 \%$ to $15 \%$. Proteins were transferred onto nitrocellulose membranes and blocked with 5\% nonfat milk powder in $1 \times$ PBS. Membranes were blotted with the following primary antibodies: mouse antibodies against PSD-95 [catalog \#75-028, NeuroMab (RRID:AB_2292909)], synaptophysin [catalog \#101011, Synaptic Systems (RRID: AB_887824)], SynDIG1 [catalog \#75-251, NeuroMab (RRID:AB_10999753)], GluA2 [catalog \#75-002, NeuroMab (RRID:AB_2232661)], PSD-93 [catalog \#75-057, NeuroMab (RRID:AB_2277296)], $\beta$-tubulin [catalog \#05661, Millipore (RRID:AB_309885)], GluN1 [catalog \#556308, BD Biosciences (RRID:AB_396353)], and Pick1 [catalog \#73-040, NeuroMab (RRID:AB_10672986)]; rabbit antibodies against SynDIG4 (Anti-Prrt1, catalog \#17261-1AP, ProteinTech), $\beta$-actin [catalog \#ab8224, Abcam (RRID:AB_449644)], GluA1 [catalog \#AB1504, Millipore (RRID:AB_2113602)], and GluN2B (provided by J.W.H.; Lim et al., 2002); and guinea pig antibodies against v-Glut1 [catalog \#AB5905, Millipore (RRID:AB_2301751)]. For chemiluminescence, goat anti-mouse horseradish peroxidase was used with SuperSignal West Pico sub- 
strate (ThermoScientific Pierce). For quantitative analyses, goat anti-rabbit (IR680) and goat anti-mouse (IR800) secondary antibodies (LI-COR) were used. Protein concentrations were quantified on an Odyssey LI-COR system using ImageStudio software. S1, P2, Syn, and PSD fractions were normalized to $\beta$-actin or $\beta$-tubulin. Then, the normalized protein level of SynDIG $1^{\beta \text {-gal }}$ mutant fraction was divided by normalized WT protein levels to determine the relative change in protein. Fractionations were performed in triplicate. Quantification data were grouped by fractionation prior to statistical analysis. No significant difference was found using $t$ test analyses.

\section{X-gal staining}

Unfixed fresh mouse brains and vertebrae were quickly frozen on dry ice in Optimal Cutting Temperature (OCT) medium, and cut in 15-25 $\mu \mathrm{m}$ sections on a Leica cryostat. Sections were mounted on Superfrost Plus slides, dried, washed in $0.1 \mathrm{M}$ phosphate buffer, $\mathrm{pH} 7.3$, with 2 $\mathrm{mM} \mathrm{MgCl}$ and $0.02 \%$ Nonidet P-40, and then stained overnight in $1.0 \mathrm{mg} / \mathrm{ml} \mathrm{X-gal} \mathrm{(5-bromo-4-chloro-3-indolyl-}$ $\beta$-D-galactopyranoside). Sections were washed, fixed in $4 \%$ paraformaldehyde, washed, counterstained with nuclear fast red, dehydrated with ethanol, and mounted. These sections were imaged on an AxioPlan2 microscope (Zeiss).

\section{Electron microscopy}

Two P56 adult wild-type and two SynDIG $1^{\beta-\text { gal }}$ homozygous mutant littermates were anesthetized and perfused with ice-cold $0.1 \mathrm{M}$ PBS followed by $4 \%$ paraformaldehyde and $2.5 \%$ glutaraldehyde in $0.1 \mathrm{~m}$ phosphate buffer. The brains were removed, and $80 \mu \mathrm{m}$ coronal sections were cut with a vibratome (Leica). Sections were dehydrated and flat embedded in Araldite. The hippocampal CA1 regions were identified, and cut and glued to blank resin blocks. Ultrathin $70 \mathrm{~nm}$ sections were obtained using a Reichert-Jung Ultramicrotome, thin sections were collected on formvar-coated, single-slot copper grids, stained with uranyl acetate and lead citrate, and examined with a Philips CM-120 electron microscope at $80 \mathrm{kV}$. Electron microscopic images were acquired using a 2000 $\times 2000$ high-resolution CCD camera (Gatan). Images were processed using DigitalMicrograph software provided by Gatan. Original images were converted to TIFF files and composed in Adobe Photoshop. Regions containing presynaptic vesicles, a synaptic cleft, and a prominent PSD area were counted as synapses. PSD width was measured and quantified with ImageJ (NIH). Perforated synapses were distinguished visually as any two juxtaposed PSDs from one postsynaptic cell drawing from the same pool of synaptic vesicles in the presynaptic terminal. Multiple spine synapses were counted when two apparently unique postsynaptic profiles were seen to be contacted by one presynaptic terminal filled with synaptic vesicles. All quantifications were performed blind to genotype.

\section{Electrophysiology}

Mice were decapitated, and brains put into an ice-cold dissection buffer as follows (in mM): $127 \mathrm{NaCl}, 1.9 \mathrm{KCl}, 1.2$
$\mathrm{KH}_{2} \mathrm{PO}_{4}, 26 \mathrm{NaHCO}_{3}, 10$ D-glucose, $23 \mathrm{MgSO}_{4}$, and 1.1 $\mathrm{CaCl}_{2}$, and saturated with $5 \% \mathrm{CO}_{2}$ and $95 \% \mathrm{O}_{2}$ to a final $\mathrm{pH}$ of 7.4. The cerebellum was removed, and slices were cut with a vibratome (VT 1000A, Leica) and subsequently maintained in artificial CSF (ACSF) as follows (in mM): 127 $\mathrm{NaCl}, 26 \mathrm{NaHCO}_{3}, 1.2 \mathrm{KH}_{2} \mathrm{PO}_{4}, 1.9 \mathrm{KCl}, 2.2 \mathrm{CaCl}_{2}, 1$ $\mathrm{MgSO}_{4}$, and 10 D-glucose, and oxygenated with $95 \% \mathrm{O}_{2}$ and $5 \% \mathrm{CO}_{2}$ to a final $\mathrm{pH}$ of 7.4 for $1 \mathrm{~h}$ at $30^{\circ} \mathrm{C}$, and then for up to $5 \mathrm{~h}$ at room temperature (RT).

\section{Field EPSP recordings in hippocampal slices}

Slices (400 $\mu \mathrm{m}$ thick) were transferred into a submerged type recording chamber constantly perfused with oxygenated ACSF containing $50 \mu \mathrm{M}$ bicuculline methobromide (Tocris Bioscience) at $30^{\circ} \mathrm{C}$. Field EPSPs (fEPSPs) were recorded in the Schaffer collateral pathway with stimulation and recording electrodes positioned within the stratum radiatum near the CA3 region and in the CA1 region, respectively. fEPSPs were recorded using ACSF-filled glass pipettes (2-3 M $\Omega$ ), amplified with an Axopatch 2B amplifier (Molecular Devices), digitized at 10 $\mathrm{kHz}$ with a Digidata 1320A digitizer (Molecular Devices), and recorded with Clampex 9 software (Molecular Devices). Stimuli (100 $\mu \mathrm{s})$ were delivered through a concentric bipolar electrode (TM53CCINS, WPI). The same intensity was used during baseline recording $(0.067 \mathrm{~Hz})$ and the induction of long-term potentiation (LTP) using 100 stimuli given at $100 \mathrm{~Hz}(1 \mathrm{~s})$. The baseline was determined by the average of fEPSP initial slopes from the 7 min period immediately before the tetanus. The level of LTP was determined by the average of fEPSP initial slopes from the period between 30 and 60 min after the tetanus. The same slices used for LTP recordings were used to record input-output relation (IOR) for stimulus intensities of 0.1-0.6 mA and paired-pulse facilitation (PPF) for interstimulus intervals of 10, 20, 50, 100, 200, and $500 \mathrm{~ms}$ (same stimulation strength as LTP recordings). For each data point, four individual traces were averaged. Data were analyzed and processed using Clampfit 9 and Microsoft Excel. Statistics and visualization were performed with GraphPad Prism. Results between genotypes were statistically compared using oneway ANOVA and Bonferroni's multiple-comparison test to compare the baseline with LTP for both genotypes as well as LTP between genotypes.

\section{Whole-cell patch-clamp recording}

Slices were transferred into a submerged type recording chamber constantly perfused with oxygenated ACSF supplemented with $50 \mu \mathrm{M}$ bicuculline methobromide (Tocris Bioscience) at room temperature. Hippocampal pyramidal neurons were visually identified using an Olympus BX50WI upright microscope and an Olympus LumPlanFL $40 \times$ water-immersion objective with infrared differential interference contrast through a Hamamatsu C2400 CCD camera. Patch micropipettes (2.5-5 M $\Omega$ ) were filled with intracellular solution (in $\mathrm{mM}: 130 \mathrm{CsMeSO}_{3}$, $2.5 \mathrm{CsCl}, 7.7 \mathrm{TEA}, 4 \mathrm{Mg}$-ATP, $0.3 \mathrm{Na}_{2}$-GTP, 20 HEPES, 8 $\mathrm{NaCl}$, and 0.2 EGTA, pH 7.2) containing $5 \mathrm{~mm}$ QX-314 (Sigma-Aldrich) to prevent action potential firing. All patch-clamp recordings were made in a whole-cell con- 
figuration using Clampex 9 to control an Axopatch 200B patch-clamp amplifier (Molecular Devices) through a Digidata 1322A digitizer. Cell capacitance and series resistance were monitored but not compensated for throughout the experiments. A stimulation electrode was positioned in the stratum radiatum. Stimulus intensity was set to evoke $50 \%$ EPSC amplitude at a holding potential of $-70 \mathrm{mV}$. Test pulses were given every $15 \mathrm{~s}$. After $5 \mathrm{~min}$ of baseline (no more than 8 min after break-in) cells were depolarized to $0 \mathrm{mV}$. After waiting $15 \mathrm{~s}$ for accommodation, 180 pulses were applied with $2 \mathrm{~Hz}(90 \mathrm{~s})$ before the holding potential was switched back to $-70 \mathrm{mV}$ and test pulses resumed after $15 \mathrm{~s}$ for $30 \mathrm{~min}$. Signals were sampled at $10 \mathrm{kHz}$ using a $2 \mathrm{kHz}$ low-pass filter. LTP was determined using Clampfit 10 as the average EPSC amplitude recorded 15-30 min after pairing the normalized to the average baseline EPSC. Results between genotypes were statistically compared using one-way ANOVA and Bonferroni's multiple-comparison test to compare baseline values with LTP values for both genotypes as well as LTP values between genotypes. The AMPA/NMDA ratio was determined by dividing the AMPA portion (measured as the peak amplitude at $-70 \mathrm{mV}$ ) by the NMDAR portion (current $200 \mathrm{~ms}$ after stimulus at $+40 \mathrm{mV}$ ). For mEPSC recordings, the extracellular ACSF was supplemented with $50 \mathrm{~mm}$ sucrose, $1 \mu \mathrm{M}$ tetrodotoxin (TTX; Tocris Bioscience), and $50 \mu \mathrm{m}$ bicuculline methobromide (Tocris Bioscience). Cells were held at $-70 \mathrm{mV}$, and miniature events were sampled for up to $30 \mathrm{~min}$ at $2 \mathrm{kHz}$ and filtered with a $1 \mathrm{kHz}$ low-pass filter. Events were identified using the inbuilt template-based event detection function in Clampfit. Statistics from 200 randomly selected events per cell were performed with Microsoft Excel and GraphPad Prism.

\section{Preparation and transfection of organotypic slice cultures}

Organotypic hippocampal slice cultures were prepared from P6 to P7 wild-type or SynDIG $1^{\beta \text {-gal }}$ homozygous mutant mice of both sexes, as described previously (Stoppini et al., 1991). Neurons were transfected using particle-mediated gene transfer (130 psi) of enhanced green fluorescent protein (EGFP; Clontech).

\section{Two-photon imaging and glutamate uncaging}

Image stacks ( $512 \times 512$ pixels, $1 \mu \mathrm{m} z$-steps) of two to six secondary and tertiary apical and basal dendritic segments from EGFP-transfected CA1 pyramidal neurons were acquired on a custom two-photon laser-scanning microscope with a pulsed Ti::sapphire laser $(930 \mathrm{~nm}$, $0.5-1.5 \mathrm{~mW}$ at the sample; SpectraPhysics). Data acquisition was controlled by Scanlmage software (Pologruto et al., 2003) written in MATLAB (MathWorks). For all experiments, a single dendrite was imaged. The first time point was acquired in slice culture medium at room temperature, after which the slice was returned to the incubator $\left(35^{\circ} \mathrm{C}\right)$. After $1 \mathrm{~h}$, the slice was placed in recirculating ACSF as follows (in mM): $127 \mathrm{NaCl}, 25 \mathrm{NaHCO}_{3}$, $1.2 \mathrm{NaH}_{2} \mathrm{PO}_{4}, 2.5 \mathrm{KCl}, 25$ D-glucose, and $2310 \mathrm{mOsm}$, $\mathrm{pH} 7.2$, with $2 \mathrm{mM} \mathrm{Ca}{ }^{2+}, 0 \mathrm{mM} \mathrm{Mg}{ }^{2+}$, and $1 \mu \mathrm{M} \mathrm{TTX}$ bubbled with carbogen gas $\left(95 \% \mathrm{O}_{2}, 5 \% \mathrm{CO}_{2}\right)$ at $33^{\circ} \mathrm{C}$.
Following spine identification, 4-methyl-7-nitroindolinyl (MNI)-glutamate (2.5-3.5 mM) was added to the bath and allowed to permeate the slice for $10 \mathrm{~min}$ before stimulating the spine. Immediately after stimulation, standard ACSF (2 $\mathrm{mm} \mathrm{Ca} 2^{+}, 1 \mathrm{mM} \mathrm{Mg2}^{+}$) was washed in, and all drugs were washed out.

\section{Preparation of mouse dissociated hippocampal cultures}

Mouse hippocampal neurons from age-matched $\mathrm{PO}-$ P2 wild-type or SynDIG1 ${ }^{\beta-g a l}$ homozygous mutant mice of both sexes were dissociated with papain and plated at a density of $1 \times 10^{5}$ cells/well in six-well plates on poly-Llysine-coated coverslips and maintained in Neurobasal medium supplemented with $1 \times$ glutamine, 2\% $\mathrm{B}-27$ Supplement, and $100 \mu \mathrm{g} / \mathrm{ml}$ penicillin/streptomycin (all reagents from Invitrogen). At $12 \mathrm{~d}$ in vitro (DIV), cultures were treated with TTX $(2 \mu \mathrm{M})$ or vehicle (DMSO) and incubated for $48 \mathrm{~h}$ prior to fixation at 14 DIV and processing for immunocytochemistry. Dissociated hippocampal neurons were fixed in $4 \%$ paraformaldehyde in $1 \times$ PBS for $10 \mathrm{~min}$ at RT. Coverslips were then rinsed in $1 \times$ PBS, permeabilized for 10 min at RT with $0.1 \%$ Triton X-100 in $1 \times$ PBS, and blocked with $5 \%$ nonfat milk powder in $1 \times$ PBS for 30 min. After incubation with primary antibodies overnight at $4^{\circ} \mathrm{C}$ and washes in $1 \times$ PBS ( $3 \times 10 \mathrm{~min})$, coverslips were incubated with secondary antibodies diluted in blocking solution for $1 \mathrm{~h}$ at room temperature. Following washes in $1 \times$ PBS $(3 \times 10$ min), coverslips were mounted on microscope slides with Fluoromount-G slide-mounting medium (SouthernBiotech). The following antibodies and dilutions were used: mouse anti-PSD-95 (1:200; NeuroMab); and guinea pig anti-VGluT1 (1:500; Millipore). Single images were acquired using a Zeiss LSM 710 confocal microscope under a $63 \times / 1.4$ oilimmersion objective, and with constant settings for gain and offset between groups. Pinhole was set at 1 A.U. and resolution of $1132 \times 1132$ pixels were used for all images. To quantitatively examine synapse density, confocal images were imported in Zeiss Axiovision 4.4 image analysis software. All channels were thresholded to include all recognizable punctate structures in the analysis. For the calculation of synapse density, a thresholded image of one channel was overlaid as a mask on the second channel. Synapse density was calculated as the percentage of PSD-95 and VGluT1 puncta that overlapped. Data were collected from two independent experiments. Graphs and statistical analyses were plotted and performed in GraphPad Prism software, and data are presented as the mean \pm SEM. Statistical significance between experimental and control datasets was assessed by paired Student's $t$ tests. Significance was defined as $p<0.05(*)$.

\section{Results}

\section{Characterization of a conditional SynDIG1 $1^{\text {flox }}$ allele}

The SynDIG1 locus is composed of 5 exons. While exons 1 and 2 are noncoding, exons 3 and 4 encode the majority of the protein up to and including the first hydrophobic segment that spans the membrane. Exon 5 encodes the C-terminal 52 aa, including the second hydrophobic segment that does not span the membrane. 
A

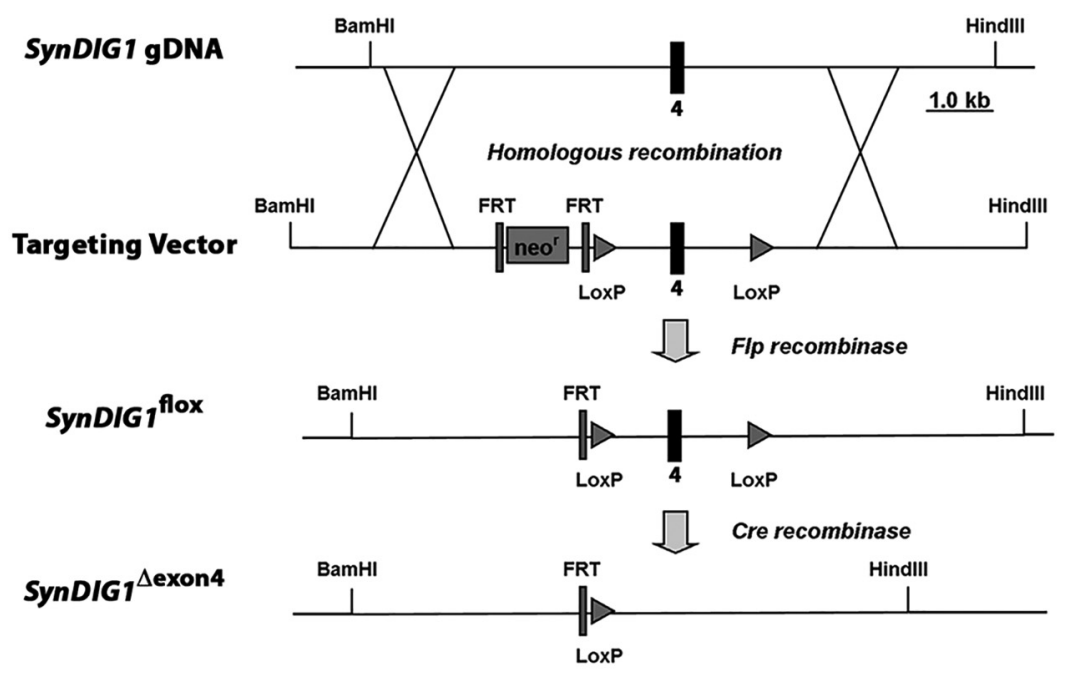

B

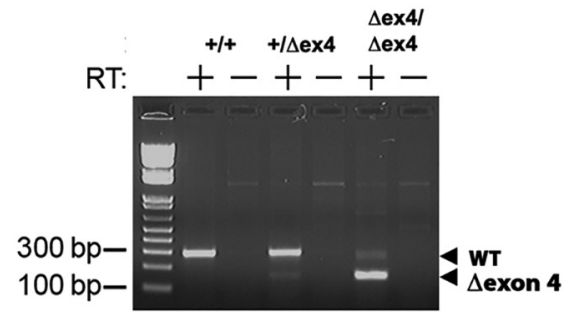

C

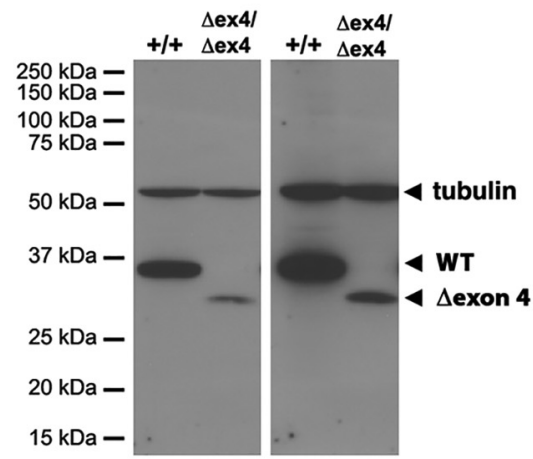

D

(1) MDGIIEQKSVLVHSKISDAGKRNGLINTRNFMAESRDGLVSVYPAPQYQSHRLVASAAPGSLEGGRSEPVQQLLDPNTLQ

(80)

(81) QSVESHYRPNIILYSDGVLRSWGDGVATDCCETTFIEDRSPTKDSLEYPDGKFIDLSGDDIKIHTLSYDVEEEEELQELE

(160)

(161) SDYSSDTESEDNFLMMPPRDHLGLSVFSMLCCFWPLGIAAFYLSHETNKAVAKGDFHQASTSSRRALFLAVLSITIGTGI

$(240)$

(241) YVGVAVALIAYLSKNNHL (258)

Figure 1. Characterization of a conditional SynDIG1 $1^{\text {flox }}$ allele. A, Schematic of the conditional SynDIG $1^{\text {flox }}$ allele, which results in the removal of exon 4 (SynDIG $1^{\text {Dexon } 4}$ ) upon exposure to Cre recombinase. B, RT-PCR using purified tissue RNA from brain tissue of

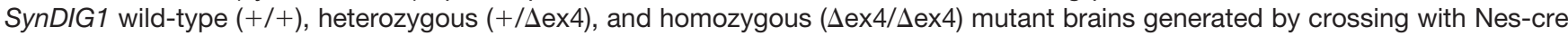
transgenic mice detects the presence or absence of an mRNA lacking exon 4 . A forward primer in exon 3 and a reverse primer in exon 5 produce a 295 or 138 bp product, respectively, in transcripts containing or lacking exon 4. Arrowheads indicate positions of WT and exon 4 lacking mutant products. Note that $(+)$ refers to the unmodified unfloxed SynDIG1 allele. $\boldsymbol{C}$, Chemiluminescence immunoblot to detect SynDIG1 expression in brain lysates from wild type $(+/+)$ and homozygous $(\Delta$ ex4/ $/$ ex4) mutant animals generated by crossing with CMV-cre transgenic mice detects the presence or absence of SynDIG1 protein lacking amino acids encoded by exon 4. Arrowheads indicate full-length protein (WT), mutant protein ( $\Delta$ exon4), and tubulin (loading control) at $2 \mathrm{~min}$ (left) and $4 \mathrm{~h}$ (right) exposure times. Note that $(+)$ refers to the unmodified unfloxed SynDIG1 allele. $\boldsymbol{D}$, Amino acid sequence of full-length SynDIG1 protein. The epitope recognized by the anti-SynDIG1 antibody is within the region and is shown in bold italic type. Transmembrane amino acids are indicated by asterisks. Amino acids encoded by exon 4 that are eliminated in SynDIG1 $1^{\Delta e x o n} 4$ upon exposure to Cre recombinase are highlighted in gray.

Transgenic mice with a conditional (floxed) allele of the SynDIG1 gene were obtained from the Mouse Biology Program at the University of California, Davis. This allele (SynDIG $1^{\text {flox }}$ ) has two loxP sites surrounding exon 4, which codes for 46 aa residues, including the transmembrane-spanning domain of the SynDIG1 protein (Fig. 1A). However, exons 3 and 5 retain the ability to be spliced in frame and could potentially code for a functional protein with an internal deletion of 46 aa $\left(S y n D / G 1^{\Delta e x o n 4}\right)$ upon exposure to Cre recombinase. We investigated this possibility at both the RNA and protein levels. First, we performed RT-PCR on total RNA from brain tissue isolated from homozygous mutant mice (SynDIG1 $1^{\text {Sexon } 4 / \Delta e x o n 4}$ ), heterozygous mutant mice $\left(\right.$ SynDIG $\left.1^{\text {exon } 4 /+}\right)$, and homozygous wild-type mice $\left(S y n D / G 1^{+/+}\right)$generated from crossing with a Nestin-cre driver line. We used primers to amplify the message be- tween exons 3 and 5, and observed an expected $295 \mathrm{bp}$ product in wild-type SynDIG $1^{+/+}$and heterozygous SynDIG $1^{\Delta \text { exon } 4 /+}$ mice, and a 138 bp product in homozygous SynDIG1 $1^{\text {eexon } 4 / \Delta e x o n 4}$ mutant mice, which consistent with the presence of SynDIG1 mRNA lacking exon 4 in homozygous mutant mice (Fig. 1B). The presence of a faint 295 bp product in homozygous mutants may be caused by incomplete excision of exon 4 by Cre recombinase. This result suggests that a stable SynDIG1 mRNA lacking exon 4 is produced in SynDIG1 $1^{\text {Lexon } 4}$ mice.

Next, we performed immunoblot analyses to investigate SynDIG1 protein expression in mice in which exon 4 was deleted in all cells generated by crossing to a CMV-cre driver line, creating a homozygous SynDIG $1^{\text {sexon } 4 / \Delta e x o n} 4$ mutant line. Unmodified SynDIG1 protein has a calculated molecular weight of $28.5 \mathrm{kDa}$, while that for the SynDIG1 protein lacking the 46 aa coded for by exon 4 is calculated 
A

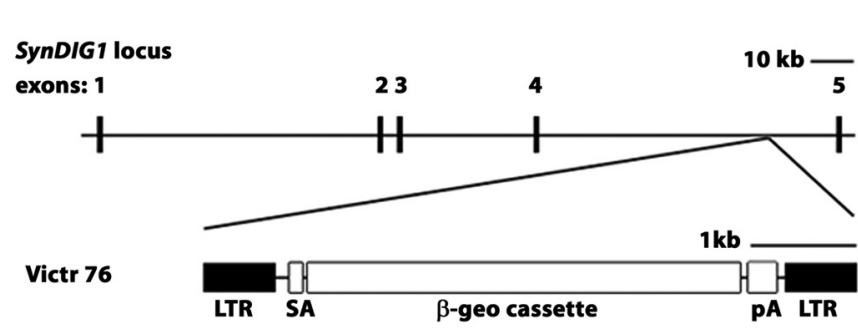

B

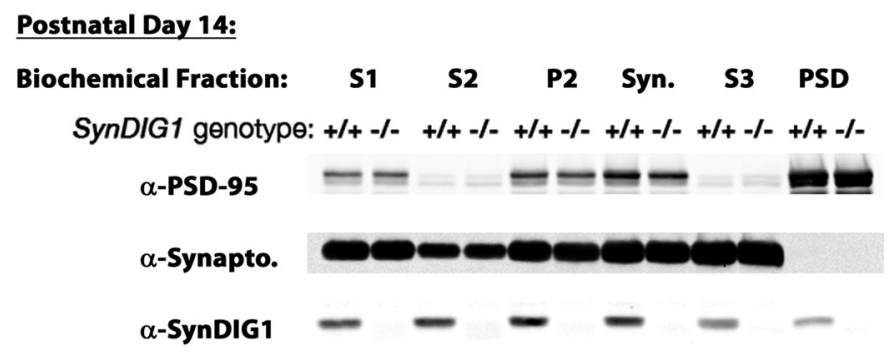

C

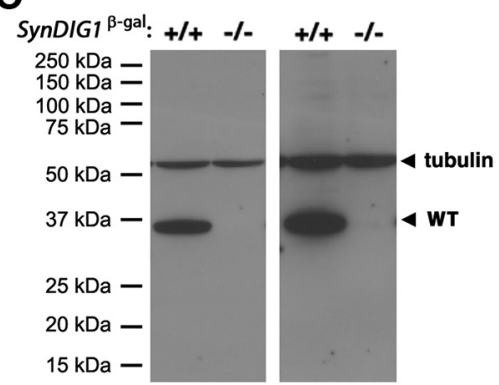

D

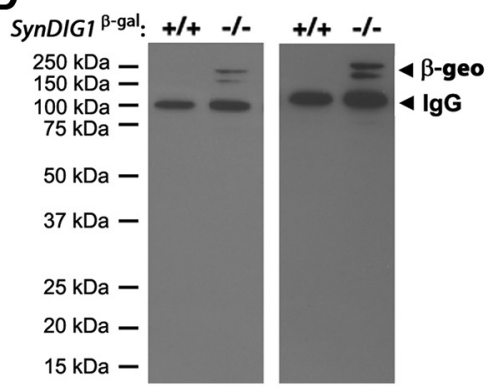

Figure 2. Characterization of SynDIG1 ${ }^{\beta-\text { gal }}$ mutant mice. A, Schematic of mouse SynDIG1 locus showing the insertion site of the $\beta$-geo cassette between exon 4 and exon 5 to create SynDIG $1^{\beta \text {-gal }}$ homozygous mutant mice. SynDIG1 expression is disrupted and replaced with $\beta$-gal expression. SA, Splice acceptor; pA, synthetic polyA signal/transcriptional blocker; LTR, viral long-terminal repeat segment. $\boldsymbol{B}$, Immunoblots of biochemical fractions from P14 wild-type $(+/+)$ and SynDIG $1^{\beta-\text { gal }}$ homozygous mutant $(-/-)$ mice using a LI-COR system. Fractions loaded are S1-, S2-, P2-, Syn-, S3-, and PSD-enriched fractions. As a control for the biochemical fractionation, PSD-95 is enriched in the PSD fraction and de-enriched in S2 and S3 while synaptophysin (Synapto) is absent from PSD and enriched in S3. Note that $(+)$ refers to the unmodified SynDIG1 allele. $\boldsymbol{C}$, Chemiluminescence immunoblot to detect SynDIG1 expression in brain lysates from wild-type $(+/+)$ and SynDIG $1^{\beta \text {-gal }}$ homozygous mutant $(-/-)$ mice. Arrowheads indicate full-length protein and tubulin (loading control) at $2 \mathrm{~min}$ (left) and $4 \mathrm{~h}$ (right) exposure times. Note that (+) refers to the unmodified SynDIG1 allele. $\boldsymbol{D}$, Chemiluminescence immunoblot to detect $\beta$-geo reactivity in brain lysates from WT $(+/+)$ and homozygous $(-/-)$ mutant mice. Arrowheads indicate bands for $\beta$-geo and mouse lgG (recognized by secondary antibody) at 2 min (left) and $4 \mathrm{~h}$ (right) exposure times. Note that $(+)$ refers to the unmodified SynDIG1 allele.

to be $23.2 \mathrm{kDa}$. Immunoblot analysis indicated that SynDIG $1^{\text {sexon4/Dexon4 }}$ mice lacked the full-length SynDIG1 protein with an apparent molecular weight of $30 \mathrm{kDa}$; however, there was expression of a protein that runs lower than the $37 \mathrm{kDa}$ but higher than the $25 \mathrm{kDa}$ molecular weight marker (Fig. 1C). This smaller band is likely the SynDIG1 protein with the 46 aa internal deletion, which includes the transmembrane domain (Fig. 1D). Given the presence of an expressed mRNA and a protein detectable by our antibody in mutant animals, we could not ignore the potential confounding effects of this gene product in downstream experiments. Hence, we did not use SynDIG $1^{\text {dexon } 4}$ mice in further studies; the remainder of the article describes results using the SynDIG1 ${ }^{\beta-g a l}$ mutant allele described below.

\section{Characterization of SynDIG1 mutant mice}

To determine the function of SynDIG1 in vivo, we acquired a commercially available SynDIG1 mutant mouse line from the TIGM. The targeting strategy used uses the Victr 76 viral vector (Hansen et al., 2008) to insert a cassette encoding a $\beta$-geo fusion protein ( $\beta$-galactosidase-Neo ${ }^{\mathrm{R}}$ ) in between exons 4 and 5 of the SynDIG1 locus to disrupt protein expression such that $\beta$-gal functions as a reporter driven by the SynDIG1 promoter
(Fig. 2A). Normal SynDIG1 expression should be greatly reduced or completely ablated due to the presence of a strong splice acceptor and transcriptional blocker (Fig. $2 \mathrm{~A})$. These mice are referred to as SynDIG1 $1^{\beta-\text { gal }}$ mutants. We did not observe any obvious phenotypic differences between mutant mice and WT littermates, and litters showed expected Mendelian ratios in sex and genotype.

Because SynDIG $1^{\beta \text {-gal }}$ mice still retain the SynDIG1 locus, biochemical fractionation followed by immunoblot analyses was performed on brain tissue from WT and homozygous mutant animals to check for retained protein expression (Fig. 2B). In P14 WT mice, SynDIG1 is present in S1-, S2-, P2-, Syn-, S3-, and PSD-enriched biochemical fractions (Fig. 2B). To ensure the enrichment of biochemical fractions, levels of PSD-95 and synaptophysin were measured. The postsynaptic protein PSD-95 is diminished in the S3 fraction and greatly enriched in the PSD fraction. The presynaptic protein synaptophysin is enriched in the Syn and S3 fractions, whereas it is undetected in the PSD fraction. When using the less sensitive but more quantifiable LI-COR-based method, SynDIG1 ${ }^{\beta-}$ gal homozygous mutant brains do not show any evident SynDIG1 expression in any fraction at P14, although the trapped allele could potentially result in a SynDIG1 protein fragment with a calculated molecular weight of $23.6 \mathrm{kDa}$ 
recognized by the SynDIG1 antibody. Using the more sensitive peroxidase-based chemiluminesence, there is a faint band detected in the SynDIG ${ }^{\beta-\text { gal }}$ homozygous mutant lysates upon long-term film overexposure (Fig. 2C); however, this band is not at the appropriate molecular weight range of the predicted SynDIG1 protein fragment. One possibility is that the SynDIG1 ${ }^{\beta-\text { gal }}$ allele is a hypomorph of SynDIG1 expression and that a small contingent of functional SynDIG1 protein remains in SynDIG ${ }^{\beta-\text { gal }}$ homozygous mutant mice. However, because the resulting SynDIG1 trapped allele is predicted to generate a much smaller protein, it is equally possible that this band represents a nonspecific protein recognized by the SynDIG1 antibody. The trapped allele does not appear to generate a fusion protein between SynDIG1 and the $\beta$-geo cassette because immunoblotting with anti- $\beta$-gal antibodies revealed a signal that is not detected by the SynDIG1 antibody (Fig. 2D).

\section{Analyses of the $\beta$-gal reporter expression in developing mouse brain}

In situ hybridization with antisense probes previously showed that SynDIG1 transcript is present within the Purkinje cell layer (PCL) of the cerebellum and throughout the hippocampus at P20 (Kalashnikova et al., 2010), and the SynDIG1 profile in the Allen Mouse Brain Atlas indicates strong expression in cerebellum (http://mouse. brain-map.org/experiment/show/70723307; http://mouse. brain-map.org/experiment/show/73931426; Lein et al., 2007). The $\beta$-gal reporter activity was investigated in cryosections from SynDIG1 ${ }^{\beta \text {-gal }}$ homozygous mutant mice stained to label functional $\beta$-gal expression. The SynDIG1 promoter is active at E15.5 within the retina and vomeronasal organ (Fig. 3A). Little $\beta$-gal expression is evident within the brain until after birth. At P15 and P28, there is $\beta$-gal expression in the cerebral cortex, anterior olfactory nucleus $(\mathrm{AON}), \mathrm{PCL}$ of the cerebellum, and throughout the hippocampus, including the CA1, CA3, and dentate gyrus (DG) regions (Fig. 3B,C). The expression of $\beta$-gal appears to increase substantially within the PCL of the cerebellum at $\mathrm{P} 60$ and $\mathrm{P} 120$ (Fig. 3D,E). Intriguingly, $\beta$-gal expression is not uniform throughout the cortical layers from P7 and continuing to P120 (Fig. 3B-E). Punctate $\beta$-gal expression was also found in the gray matter portions of the spinal cord and within dorsal root ganglia at ages P7, P15, and P120 (Fig. 3F).

\section{SynDIG1-deficient synapses are structurally immature}

To investigate structural changes in excitatory synapses, the CA1 region of the hippocampus was analyzed in two 2-month-old SynDIG1 ${ }^{\beta-g a l}$ homozygous mutant mice and two WT littermates with electron microscopy (Fig. 4A-C). Synapse ultrastructure in multiple electron micrographs was determined by several criteria, including the number of asymmetrical synapses per unit area, the length of the PSD in each synapse, and the percentage of perforated and multiple spine synapses. Perforated synapses are defined by a discontinuous PSD and reflect mature synapses that have undergone structural changes in response to activity and contain a higher number of
AMPA receptors compared with classic synapses (Ganeshina et al., 2004a,b). Multiple spine synapses occur when two PSDs from two unique postsynaptic cells draw from one pool of presynaptic vesicles derived from one presynaptic cell. Quantification of multiple images revealed a trend toward an increase in excitatory synapse number in mutant compared with WT mice ( $p=0.057$; Fig. 4D). There is a statistically significant decrease in average PSD length in excitatory synapses of SynDIG1 ${ }^{\beta-g a l}$ homozygous mutant mice (Fig. 4E). Moreover, we also found a statistically significant decrease in the number of perforated synapses in SynDIG $1^{\beta \text {-gal }}$ homozygous mutant mice (Fig. 4F) and a trend toward an increase in the number of multiple spine synapses in SynDIG $1^{\beta-g a l}$ mutant mice compared with WT mice ( $p=0.059$; Fig. $4 \mathrm{G})$. These data are consistent with an overall decrease in synapse maturity in SynDIG $1^{\beta \text {-gal }}$ homozygous mutant mice.

\section{SynDIG1-deficient synapses are functionally immature}

To determine the functionality of SynDIG1 $1^{\beta-\text { gal }}$ synapses, we performed fEPSP recordings in hippocampal slices of 8- to 12-week-old SynDIG1 ${ }^{\beta \text {-gal }}$ mutants. LTP was elicited in the presence of the $\mathrm{GABA}_{A}$ receptor antagonist bicuculline by a weak tetanic stimulation ( $1 \mathrm{~s}, 100$ $\mathrm{Hz}$ ) in order to distinguish subtle changes in synaptic plasticity that might remain concealed when stronger stimulus paradigms are used. Using 8- to 12-week-old animals, we found no alterations in the magnitude of LTP expressed by SynDIG1 ${ }^{\beta-\text { gal }}$ mutants compared with WT controls (Fig. 5A). In slices from the same animals, the probability of presynaptic transmitter release, as monitored by PPF, was comparable between the genotypes (Fig. 5B). Additionally, we found no changes in the IOR of the fEPSP strength in response to increasing stimulus intensities between mutants and controls (Fig. 5B). Remarkably, when using the same weak $(1 \mathrm{~s}, 100 \mathrm{~Hz})$ LTP paradigm in 2-week-old animals, we found a complete lack of LTP in SynDIG ${ }^{\beta-g a l}$ homozygous mutant mice in contrast to WT controls (Fig. 5C). To evaluate whether this effect is due to disturbed synaptic plasticity or a deficit in synaptic transmission, we performed wholecell patch-clamp experiments on CA1 pyramidal neurons of SynDIG $1^{\beta-g a l}$ mice.

First, we looked at pairing-induced LTP. In this experiment, cells are held at $0 \mathrm{mV}$ to release the $\mathrm{Mg}^{2+}$ block of the NMDA receptor. In this configuration, the stimulation of presynaptic terminals at $2 \mathrm{~Hz}$ for $90 \mathrm{~s}$ readily leads to postsynaptic potentiation of the EPSC triggered by $\mathrm{Ca}^{2+}$ influx through NMDA receptors. SynDIG ${ }^{\beta-g a l}$ exhibited the same amount of pairing-induced LTP as did WT controls (Fig. 5D), arguing that SynDIG1 ${ }^{\beta-\text { gal }}$ mice do not lack the mechanisms for synaptic plasticity downstream of the NMDA receptor. What became immediately apparent, however, was that EPSC amplitudes of 2-week-old SynDIG ${ }^{\beta-g a l}$ mice are significantly smaller than those of WT controls, while the AMPA/NMDA ratio is unchanged (Fig. 5E,F). Additionally, we were unable to identify any defect in presynaptic function as we could observe nor- 


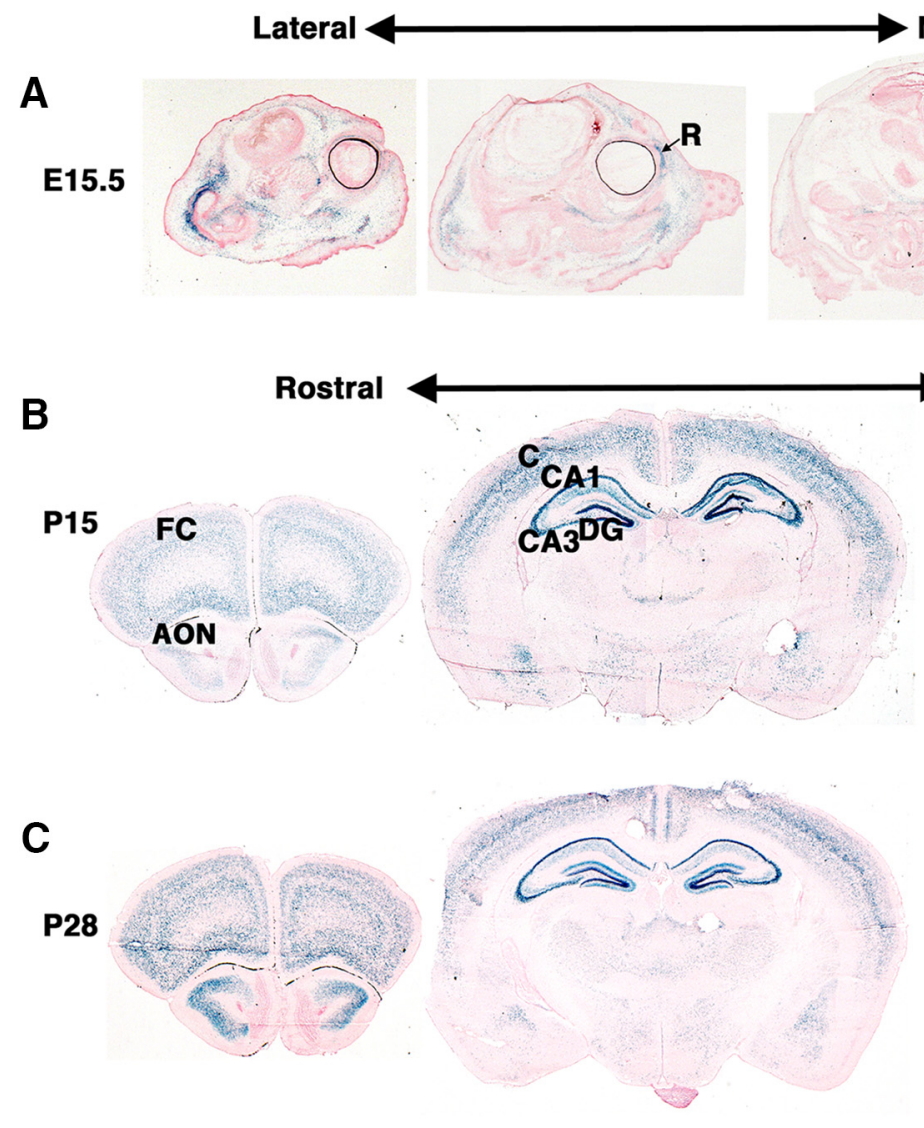

\section{Medial}

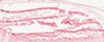

A

E15.5

VNO

$1 \mathrm{~mm}$

\section{Caudal}
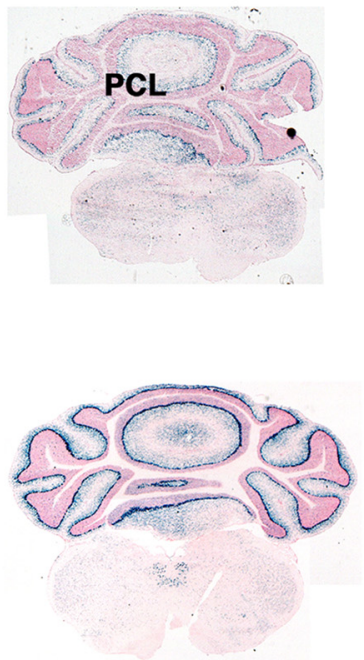

$1 \mathrm{~mm}$

D

P60
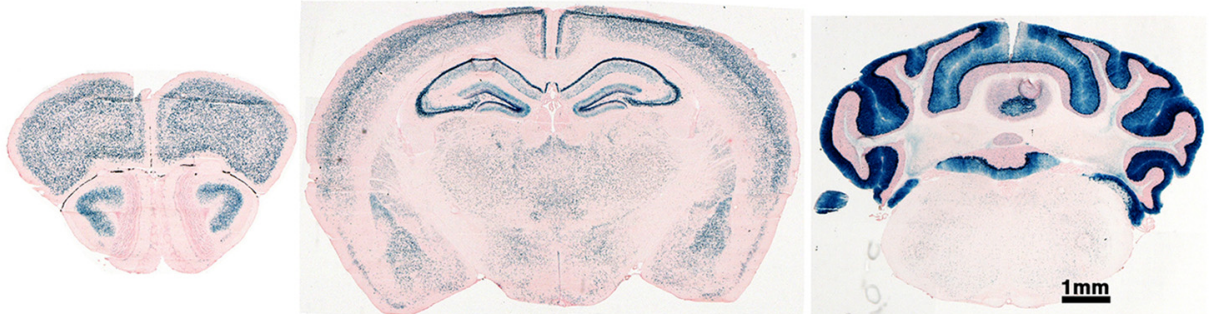

E

P120
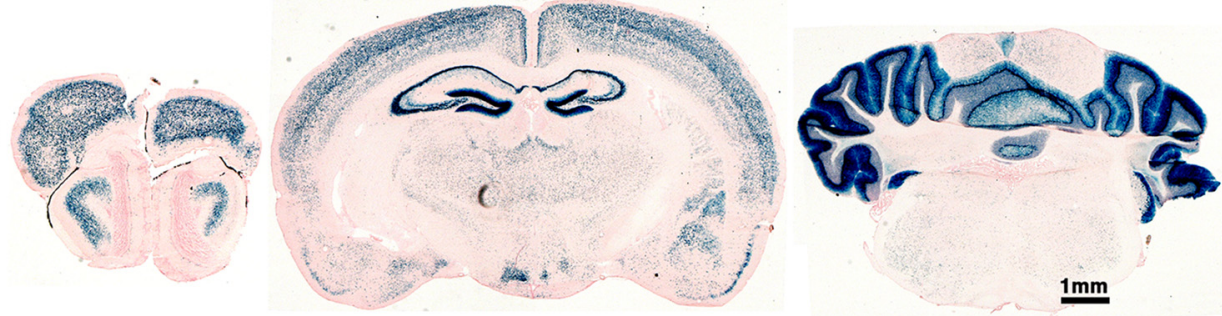

\section{F Spinal Cord}

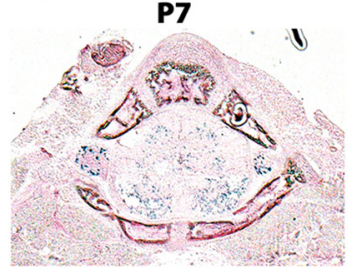

P15
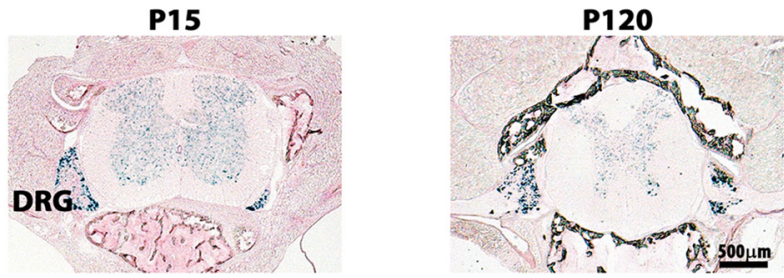

Figure 3. Expression profile of SynDIG1 reporter in the developing mouse brain. $\boldsymbol{A}$, Sagittal sections from the entire head of E15.5 SynDIG $1^{\beta \text {-gal }}$ homozygous mutant mouse show $\beta$-gal reporter activity (blue) within the retina (R) and vomeronasal organ (VNO), but 
continued

little $\beta$-gal activity in the brain. $\boldsymbol{B}-\boldsymbol{E}$, Coronal sections of P15 (B), P28 (C), P60 (D), and P120 (E) mutant mouse brains show $\beta$-gal expression in the CA1, CA3, and DG in the hippocampus; in the PCL of the cerebellum; in the frontal cortex (FC); in the AON; and in the cortex (C). Scale bars, $1 \mathrm{~mm}$. F, Cross sections of P7, P15, and P120 vertebrae show $\beta$-gal expression in the dorsal root ganglia (DRG) and within the spinal cord. Scale bar, $500 \mathrm{~nm}$. All sections are counterstained with nuclear fast red.

mal PPF (Fig. 5G). These observations are consistent with a model where SynDIG1-deficient synapses are less mature and show a reduced density of AMPA- and NMDAtype glutamate receptors. The remaining channels are sufficient to trigger synaptic plasticity upon NMDA receptor activation; however, the reduced amount of AMPA receptor present in the postsynapse is insufficient to depolarize the postsynaptic cell enough to release the $\mathrm{Mg}^{2+}$ block from the NMDA receptor. Therefore, the weak $1 \mathrm{~s}$ $100 \mathrm{~Hz}$ tetanus did not elicit LTP, while pairing-induced LTP was not affected as there the $\mathrm{Mg}^{2+}$ block is released by depolarization.

To evaluate potential changes in postsynaptic AMPA receptor function more carefully, we monitored mEPSC by whole-cell patch-clamp recordings (Fig. $5 \mathrm{H}$, representative recordings). Accordingly, mEPSC amplitude in SynDIG ${ }^{\beta-\text { gal }}$ homozygous mutant CA1 pyramidal neurons was significantly reduced compared with WT controls
(Fig. 5l). At the same time, we found an increase in mEPSC frequency (Fig. 5J, visualized as the interevent interval, the inverse of frequency), possibly due to mechanisms compensating for the loss in AMPA receptor density. Additionally, mEPSC of SynDIG1 ${ }^{\beta-g a l}$ homozygous mutant mice display a significantly faster decay time than do WT controls (Fig. 5K). Faster EPSC decay additionally reduces the amount of current conducted by the AMPA receptor, which might contribute to the reduced depolarization of postsynaptic cells.

\section{SynDIG1-deficient synapses exhibit increased short- term structural plasticity}

Given the changes in excitatory synapse structure and function, we investigated whether there were changes in other aspects of synapse development. Specifically, we observed structural remodeling upon two-photon photolysis of caged glutamate (MNI-glutamate) at single spines

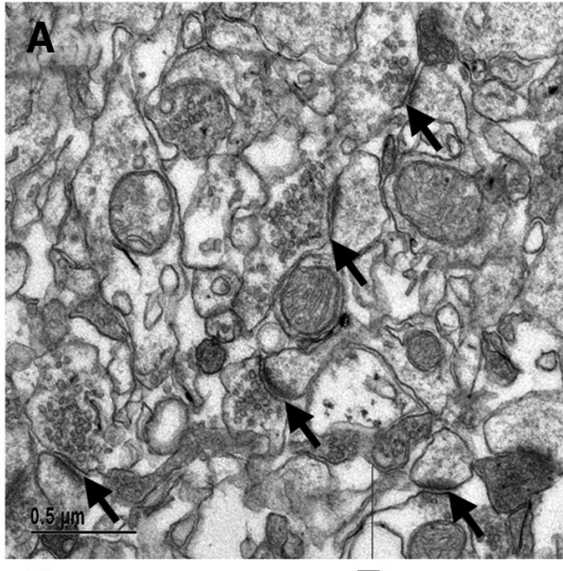

Do. of Synapses

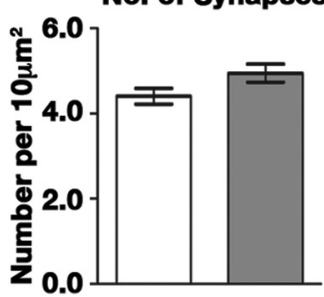

E

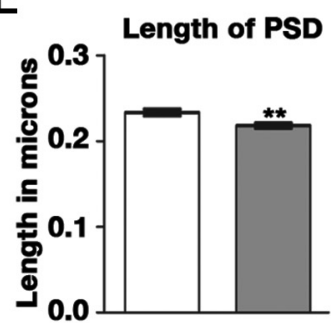

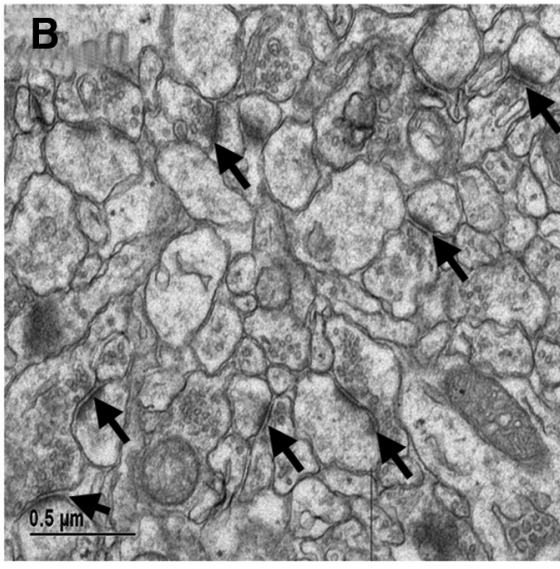

$\mathbf{F}$

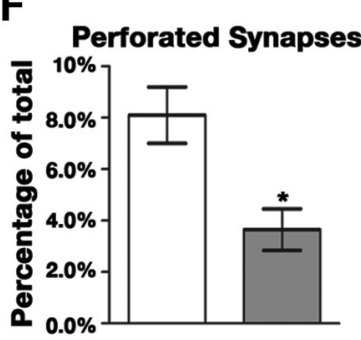

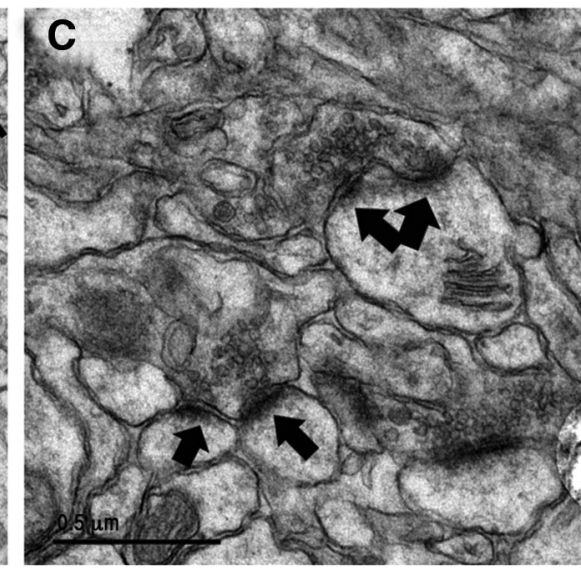

G

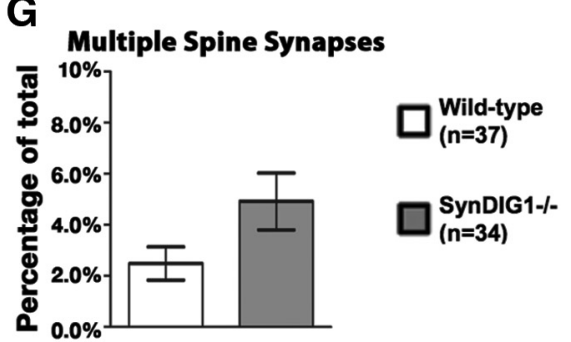

Figure 4. Synapse ultrastructure is altered in SynDIG1 mutant mice. $\boldsymbol{A}, \boldsymbol{B}$, Representative electron micrographs from the CA1 region of the hippocampus from P56 WT $(\boldsymbol{A})$ and SynDIG $1^{\beta \text {-gal }}$ homozygous mutant littermates $(\boldsymbol{B})$. Example synapses are indicated by black arrows. C, Higher-magnification image from WT mouse hippocampus illustrating a stereotypical perforated synapse (conjoined black arrows) and multiple spine synapses (two separated arrows). Scale bar, $0.5 \mu \mathrm{m}$. $\boldsymbol{D}-\mathbf{G}$, Quantification of multiple images (WT, $n=37$; SynDIG $1^{\beta \text {-gal }}$ homozygous mutant, $\left.n=34\right)$ reveal a trend toward increased synapse number $\left(\mathrm{WT}, 4.40\right.$ synapses/10 $\mu \mathrm{m}^{2} ;$ mutant, 4.94 synapses $\left./ 10 \mu \mathrm{m}^{2} ; p=0.057 ; \boldsymbol{D}\right)$, a statistically significant decrease in average PSD length $\left(\mathrm{WT}, 0.233 \mu \mathrm{m} ; \mathrm{SynDIG}{ }^{\beta-g a l}\right.$ homozygous mutant, $0.218 \mu \mathrm{m} ; p=0.016 ; \boldsymbol{E}$ ), a statistically significant decrease in the number of perforated synapses (WT, $8.10 \%$ perforated synapses; SynDIG $1^{\beta \text {-gal }}$ homozygous mutant, 3.65\% perforated synapses; $p=0.002 ; \boldsymbol{F}$ ), and a trend toward an increased number of multiple spine synapses (WT, 2.49\% multiple spine synapses; SynDIG $1^{\beta \text {-gal }}$ homozygous mutant, $4.92 \%$ multiple spine synapses; $p=0.059 ; \mathbf{G})$ in SynDIG1 ${ }^{\beta \text {-gal }}$ homozygous mutant mice compared with WT. Error bars represent the SEM. 

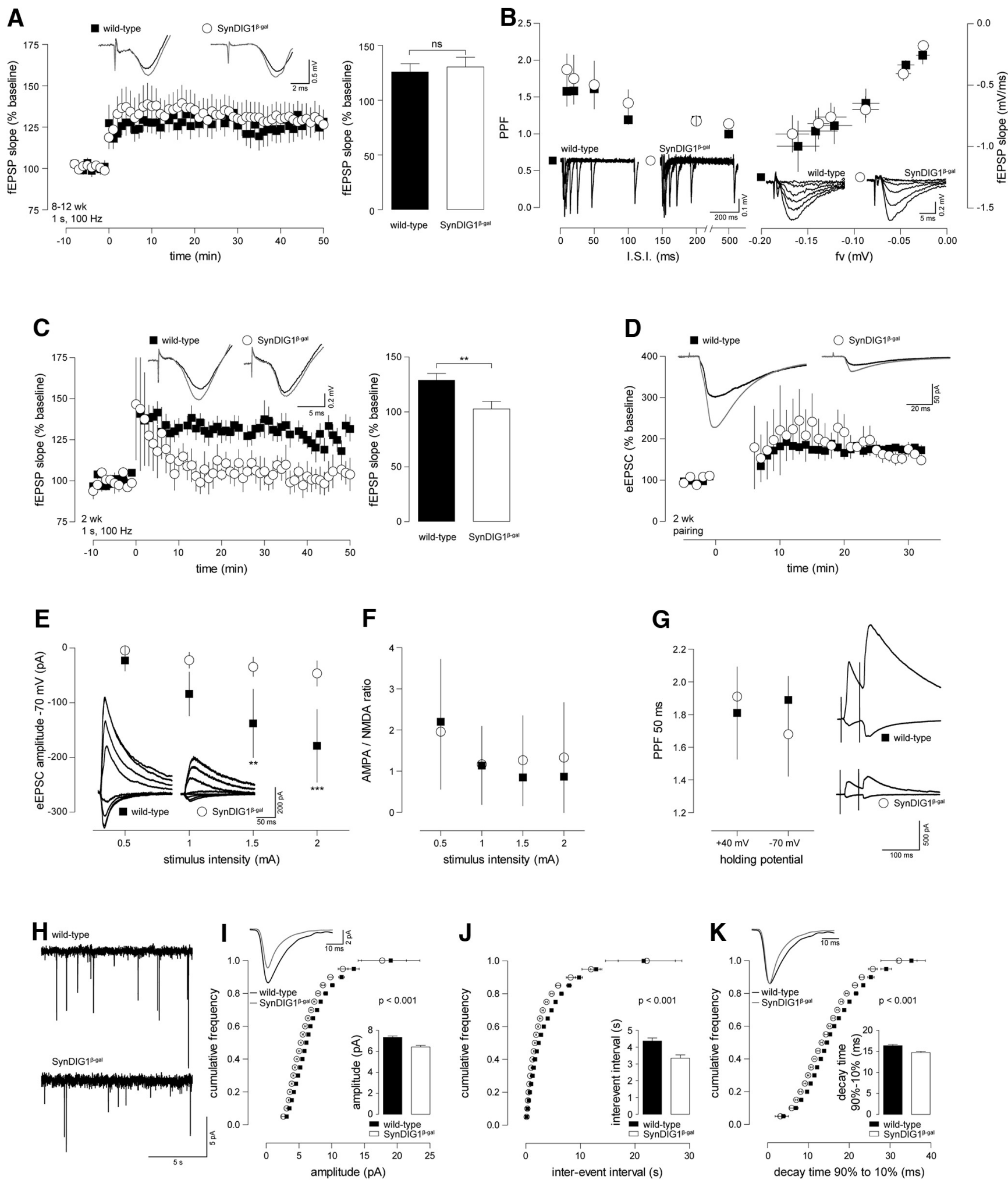

Figure 5. Synaptic transmission and plasticity is disturbed in 2-week-old but not in adult SynDIG $1^{\beta-g a l}$ mutant mice. Acute brain slices from SynDIG $1^{\beta-\text { gal }}$ homozygous mutant $\left(O\right.$, SynDIG $\left.1^{\beta-\text { gal }}\right)$ and litter-matched WT controls $(\boldsymbol{-})$ were used to record Schaffer collateral LTP and whole-cell patch-clamp experiments on CA1 pyramidal cells. A, fEPSP recorded in slices from 8- to 12-week-old mice. SynDIG $1^{\beta-\text { gal }}$ homozygous mutant and WT controls showed significant LTP after a $1 \mathrm{~s} 100 \mathrm{~Hz}$ tetanic stimulation. The level of potentiation was not different between the genotypes (WT: baseline, $99.6 \pm 0.8 \%$; LTP, $125.6 \pm 7.6 \% ; p<0.05$ vs baseline; $n=12$; SynDIG $1^{\beta-\text { gal }}$ homozygous mutant: baseline, $100.5 \pm 0.4 \%$; LTP, $130.2 \pm 8.9 \% ; p<0.01$ vs baseline; $n=13$ ). Insets at top show traces from representative recordings before and after (gray traces) tetanization. The left panel shows averaged time courses of all 


\section{continued}

experiments with traces from representative recordings on top. Statistics are illustrated in the bar diagram on the right. $\boldsymbol{B}$, SynDIG $1^{\beta \text {-gal }}$ homozygous mutant mice displayed normal PPF (left) and IOR (right) when compared with WT animals. Insets beneath data points show representative recordings. C, fEPSP recorded from 2-week-old mice. A $1 \mathrm{~s} 100 \mathrm{~Hz}$ tetanus leads to potentiation of fEPSP in WT [baseline, $99.9 \pm 0.9 \%$; LTP, $128.3 \pm 6.7 \% ; p<0.001$ (WT baseline vs LTP); $n=10$ ] but not SynDIG1 ${ }^{\beta-g a l}$ homozygous mutant mice [baseline, $99.4 \pm 0.5 \%$; LTP, $102.6 \pm 7.0 \% ; p<0.01$ (SynDIG1 ${ }^{\beta-\text { gal }}$ homozygous mutant vs WT LTP); $n=6$ ]. The left panel shows the averaged time courses of all experiments with traces from representative recordings at the top. Statistics are illustrated in the bar diagram on the right. $\boldsymbol{D}$, Pairing-induced LTP of evoked EPSC (eEPSC) in hippocampal slices of 2-week-old animals was normal in SynDIG1 ${ }^{\beta-g a l}$ (baseline, $99.4 \pm 0.6 \%$; LTP, $168.5 \pm 15.4 \% ; p<0.001$ vs baseline; $n=3$ ) compared with WT mice (baseline, $100.1 \pm 0.04 \%$; LTP, $175.7 \pm 10.6 \% ; p<0.001$ vs baseline; $n=4$ ). Insets at the top show traces from representative recordings before and after (gray traces) pairing. $\boldsymbol{E}$, EPSCs were evoked by increasing stimulus intensities recorded at holding potentials of -70 and $+40 \mathrm{mV}$. At a holding potential of $-40 \mathrm{mV}$, eEPSC amplitudes were significantly higher in WT mice than in SynDIG $1^{\beta \text {-gal }}$ mutants [stimulus intensity $(\mathrm{si})=0.5 \mathrm{~mA},-22.8 \pm 19.3 \mathrm{pA} ; \mathrm{si}=1 \mathrm{~mA},-84.2 \pm 40.1 \mathrm{pA} ; \mathrm{si}=1.5 \mathrm{~mA},-137.9 \pm 62.4$ $\mathrm{pA} ; \mathrm{si}=2 \mathrm{~mA},-179.8 \pm 66.6 \mathrm{pA} ; n=9 ;$ SynDIG1 $^{\beta-g a l} ;$ si $=0.5 \mathrm{~mA},-4.7 \pm 1.2 \mathrm{pA} ; \mathrm{si}=1 \mathrm{~mA},-22.5 \pm 15.6 \mathrm{pA} ; \mathrm{si}=1.5 \mathrm{~mA},-34.6$ $\pm 17.6 \mathrm{pA} ; \mathrm{si}=2 \mathrm{~mA},-46.6 \pm 23.1 \mathrm{pA} ; n=4$; two-way ANOVA and Bonferroni's post-test: $F_{(1,44)}=35.4 ; 1.5 \mathrm{pA}, p<0.01 ; 2 \mathrm{pA}$, $p<0.001$ ]. Insets at the bottom show traces from representative recordings. $\boldsymbol{F}$, The AMPAR/NMDAR ratio did not differ between WT and SynDIG ${ }^{\beta-g a l}$ in the recordings from $\boldsymbol{E}$ for all stimulus intensities. $\boldsymbol{G}$, No difference was found in PPF (50 ms interstimulus interval) between WT and SynDIG1 ${ }^{\beta-g a l}$. Insets on the right show traces from representative recordings. $\boldsymbol{H}$, Sample recordings of mEPSCs recorded from CA1 pyramidal neurons in acute slices of 2-week-old WT and SynDIG $1^{\beta \text {-gal }}$ homozygous mutant mice. I-K, Cumulative histograms show significant reduction in amplitude $(\boldsymbol{I})$, interevent interval $(\boldsymbol{J})$, and decay time $(\boldsymbol{K})$ of $\mathrm{mEPSC}$ recorded in SynDIG1 ${ }^{\beta-g a l}$ homozygous mutant compared with WT mice (bin size, $0.5 ; t$ tests for each binned data point). Inset at top contains traces averaged from all mEPSCs of one representative experiment for each genotype drawn to scale $(I)$ and normalized to peak (K). Averages are shown in bar diagrams at the bottom (amplitude: WT, $7.3 \pm 0.1 \mathrm{pA}, n=8$; SynDIG1 ${ }^{\beta \text {-gal }}$ homozygous mutant, $6.4 \pm 0.1 \mathrm{pA}, n=6$. Interevent interval: WT, $4.3 \pm 0.2 \mathrm{~s}$; SynDIG1 ${ }^{\beta \text {-gal }}$ homozygous mutant, $3.3 \pm 0.2 \mathrm{~ms}$. Decay time: WT, $16.4 \pm 0.3 \mathrm{~ms} ;$ SynDIG1 ${ }^{\beta-g a l}$ homozygous mutant, $14.7 \pm 0.3 \mathrm{~ms})$.

of hippocampal CA1 pyramidal neurons (Fig. 6). Hippocampal slice cultures from P6 to P7 WT and SynDIG ${ }^{\beta-}$ gal homozygous mutant mice were transfected with EGFP to visualize spines on dendritic segments from CA1 pyramidal neurons using a two-photon laser-scanning microscope. Stimulation with a protocol that mimics LTP results in long-lasting increased spine volume, as measured by EGFP fluorescence that is dependent on original spine volume (Matsuzaki et al., 2004). Small spines (defined as spines that are $<85 \%$ of the average neighbor brightness) consistently exhibit increased long-lasting enlargement of spine volume upon LTP stimulation in contrast to large spines (defined as spines that are $>85 \%$ of the average neighbor brightness; Matsuzaki et al., 2004). Small spines from WT animals exhibited an initial twofold increased spine volume upon LTP stimulation compared with baseline that remains statistically different at later time points (Fig. 6A-C), whereas large WT spines did not respond to LTP stimulation at any time point (Fig. $6 \mathrm{D}-F)$. Interestingly, small spines from SynDIG $1^{\beta-\text { gal }}$ homozygous mutant animals have a trend toward increased initial spine brightness upon LTP stimulation $(p=0.07$; Fig. $6 \mathrm{~A}-C)$. Strikingly, large spines from SynDIG $1^{\beta-\text { gal }}$ homozygous mutants exhibit a significant threefold short-term increase in spine brightness compared with baseline in contrast to large spines from WT animals $(p=0.01$; Fig. $6 D-F)$.

\section{Synapse composition of SynDIG1-deficient synapses is unchanged}

Because of the significant changes that we found in the structure and function of excitatory synapses, we investigated whether protein levels of candidate AMPA and NMDA receptor subunits and MAGUK scaffolding proteins PSD-93 and PSD-95 were altered in SynDIG1deficient synapses. Protein was isolated from P13-P15
WT and SynDIG1 $1^{\beta-g a l}$ homozygous mutant mouse forebrains in three independent biochemical fractionation experiments. We tested for changes in protein levels between WT and mutant samples in the following four fractions: postnuclear, membrane enriched, synaptosomal enriched, and postsynaptic density enriched (Fig. 7). These levels were compared with the cytoskeletal proteins $\beta$-actin and $\beta$-tubulin, which are present in all fractions. SynDIG1 is greatly diminished in all fractions from mutant tissue at this age. The SynDIG1 ortholog SynDIG4 [also known as Prrt1 (proline-rich transmembrane protein 1)] is also present in all fractions, and remains unchanged between WT and mutant samples, as is the scaffolding protein PICK-1 (protein kinase C binding protein 1; Fig. 7A). Proteins from each fraction were normalized to $\beta$-tubulin or $\beta$-actin, and the ratio to WT levels was determined. There is no statistically significant difference in protein levels between WT and mutant mice in the AMPA receptor subunits GluA1 and GluA2 (Fig. 7B), the NMDA receptor subunits GluN1 and GluN2A (Fig. 7C), or the MAGUKs PSD-93 and PSD-95 (Fig. 7D). While there may be minor trends of difference between WT and mutant protein levels in some biochemical fractions, the PSD fractions show similar protein levels of all tested candidate proteins.

\section{Activity-dependent synapse development is impaired in SynDIG1-deficient neurons}

SynDIG1 localization at excitatory synapses is sensitive to activity level in hippocampal neurons (Kalashnikova et al., 2010). To test whether SynDIG1 deficiency resulted in deficits in activity-dependent synapse development, dissociated cultures of hippocampal neurons from WT and mutant mice were prepared. At 12 DIV, cultures were treated with $2 \mu \mathrm{M}$ TTX or vehicle and fixed at 14 DIV for immunocytochemistry to label synapses with antibodies 
A

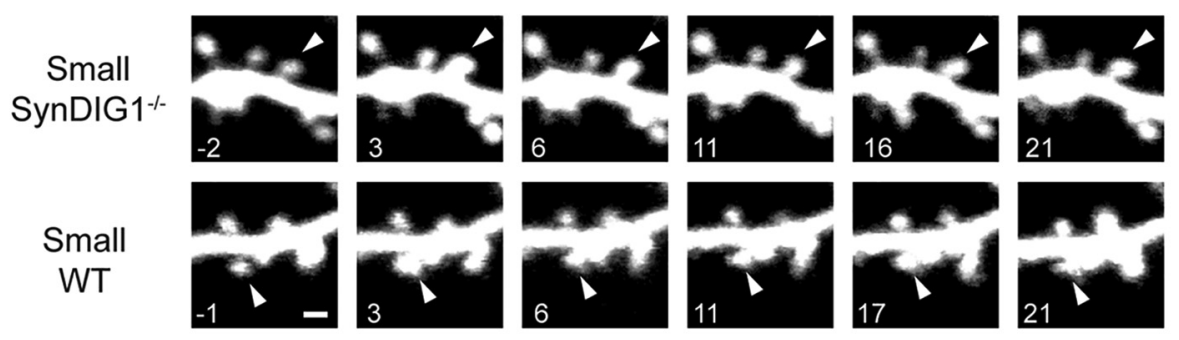

B

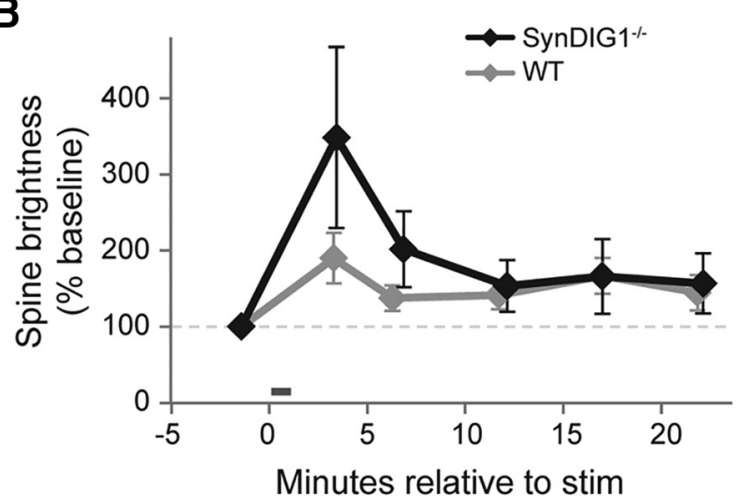

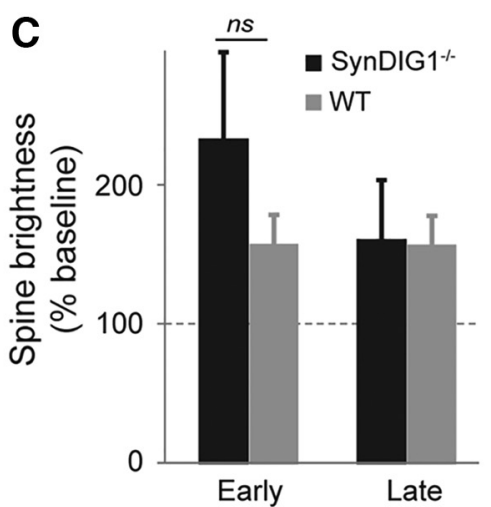

D

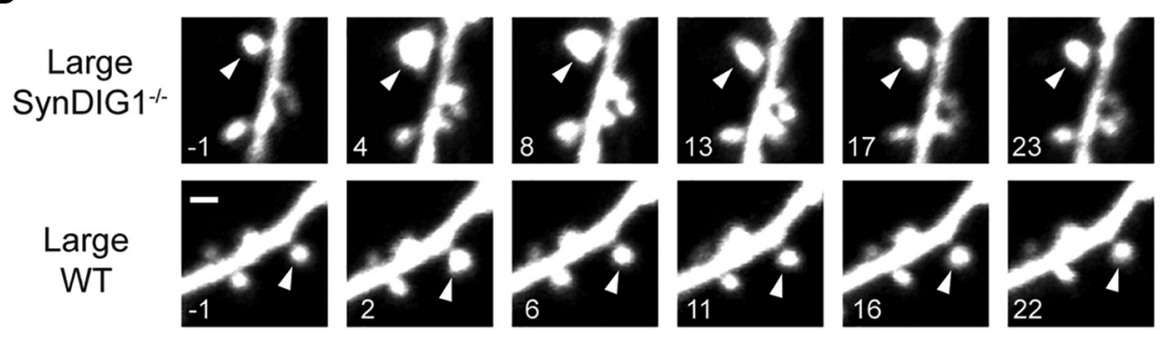

E

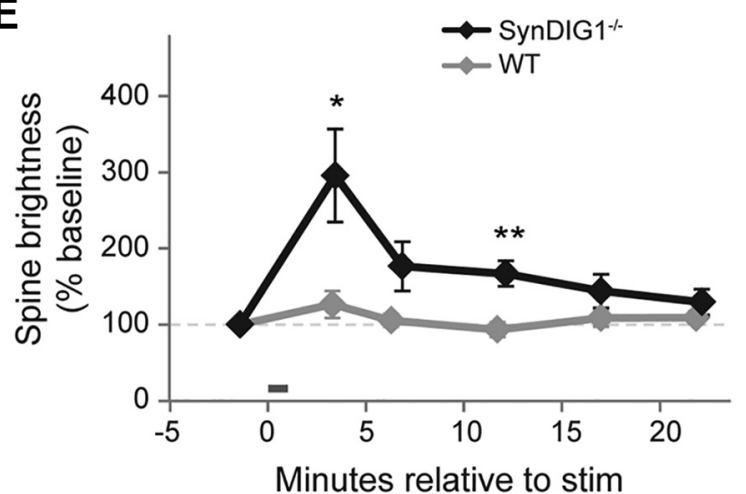

$\mathbf{F}$

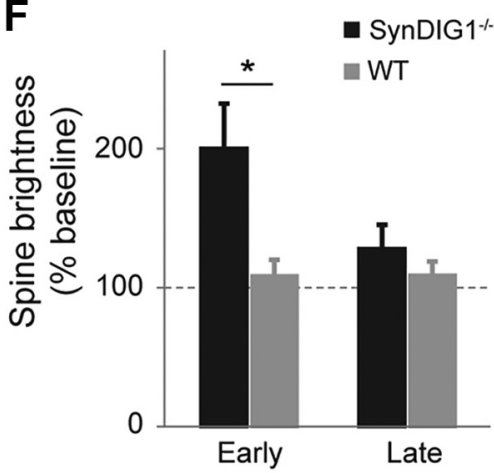

Figure 6. SynDIG1 limits early-phase structural plasticity in large spines. $\boldsymbol{A}$, Representative images illustrating small stimulated spines (arrowheads) on EGFP-expressing neurons from SynDIG1 ${ }^{\beta-\text { gal }}$ homozygous mutant neurons (top) and neurons from WT mice (bottom). Time stamps are in minutes relative to LTP stimulation. Small spines are defined as $<85 \%$ of average neighbor brightness. Scale bar, $1 \mu \mathrm{m}$. B. Time course of small spine structural plasticity. There are no significance differences between genotypes (WT, $n=14$ stimulated target spines on 14 cells; SynDIG $1^{\beta \text {-gal }}$ homozygous mutant, $n=13$ stimulated target spines on 13 cells; $p>0.2$ for all comparisons). Error bars indicate \pm SEM. C. The average early ( $<15 \mathrm{~min}$ after stimulation) and late $(>15 \mathrm{~min}$ after stimulation) change in small spine brightness by genotype. There are no significant differences between genotypes ( $p>0.4$ for all comparisons). Error bars represent \pm SEM. $\boldsymbol{D}$, Representative images illustrating large stimulated target spines (arrowheads) on EGFP-expressing neurons from SynDIG ${ }^{\beta \text {-gal }}$ homozygous mutant neurons (top) and WT neurons (bottom). Time stamps are in minutes relative to LTP stimulation. Large spines are defined as $>85 \%$ of average neighbor brightness. Scale bar, $1 \mu \mathrm{m}$. $\boldsymbol{E}$, Time course of large spine 
continued

structural plasticity. Large stimulated spines on WT neurons did not enlarge after stimulation (black line; $n=8$ spines on 8 cells). Large stimulated spines on SynDIG $1^{\beta \text {-gal }}$ homozygous mutant neurons enlarged significantly 3 and 12 min after stimulation (gray line; $n=$ 7 spines on 7 cells; $p<0.05)$. Error bars represent the SEM. $\boldsymbol{F}$, The average early $(<15$ min after stimulation) and late $(>15$ min after stimulation) change in large spine brightness by genotype. Large stimulated spines on SynDIG $1^{\beta \text {-gal }}$ homozygous mutant neurons enlarged significantly more than those of WT neurons during early-phase, but not late-phase, structural plasticity $(p<0.05)$. Error bars represent \pm SEM.

against VGluT1 and PSD-95 as presynaptic and postsynaptic markers, respectively (Fig. 8A). Quantification of multiple images from two independent experiments revealed increased synapse density (measured as the overlap of VGluT1 and PSD-95 puncta) in WT neurons treated with TTX compared with vehicle-treated cultures, while synapse density failed to increase upon TTX treatment in
SynDIG1 $1^{\beta \text {-gal }}$ homozygous mutant neurons compared with vehicle-treated cultures (Fig. 8B), indicating that activitydependent synapse development requires SynDIG1.

\section{Discussion}

It proved to be unfortunate that the putative conditional null SynDIG $1^{\text {Dexon } 4}$ mutant mouse line had a retained

A

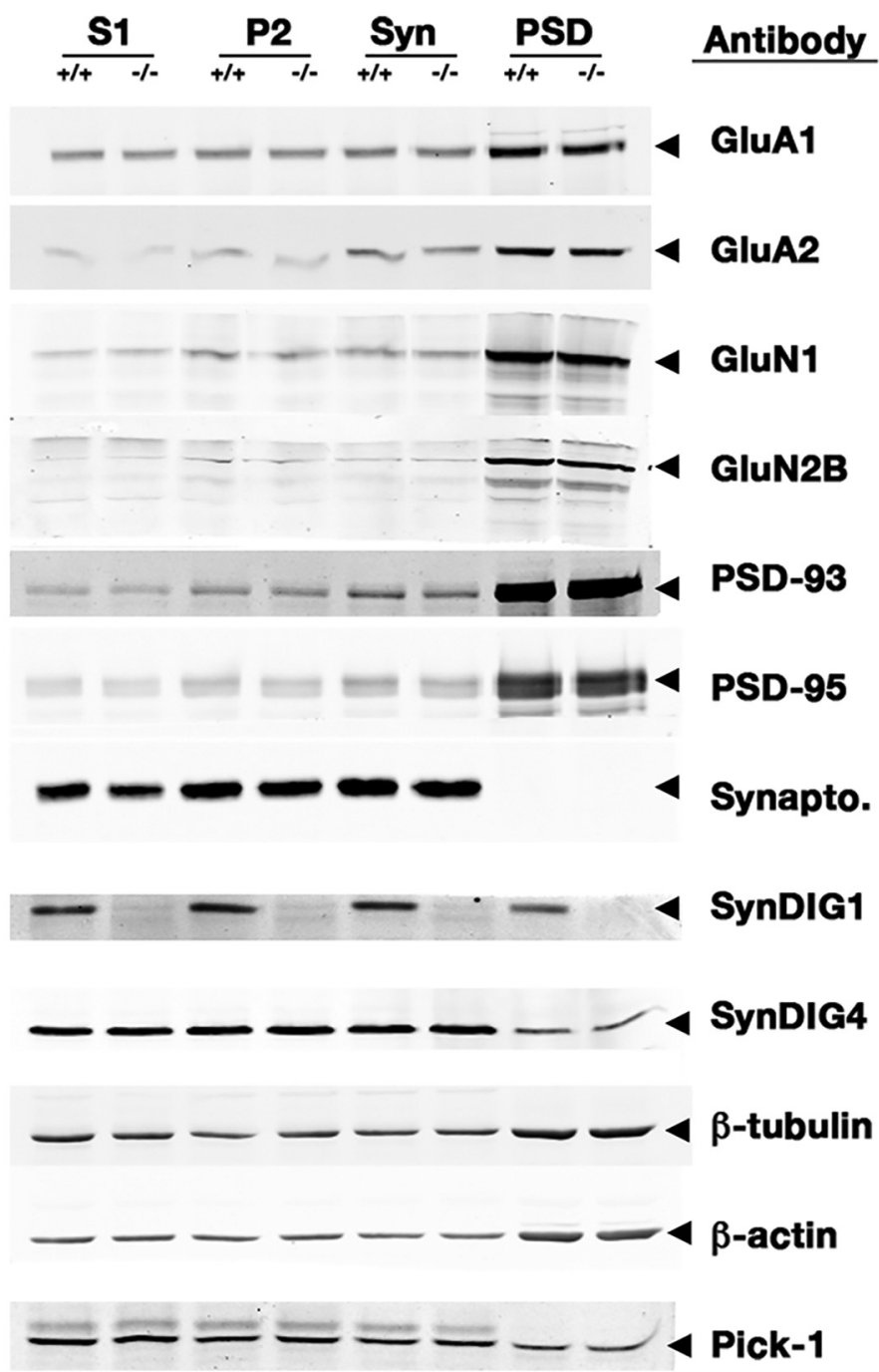

B

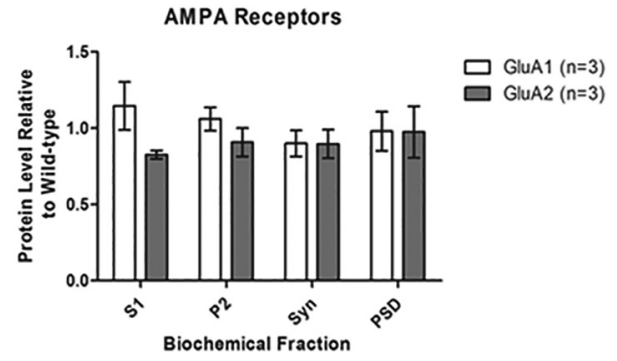

C

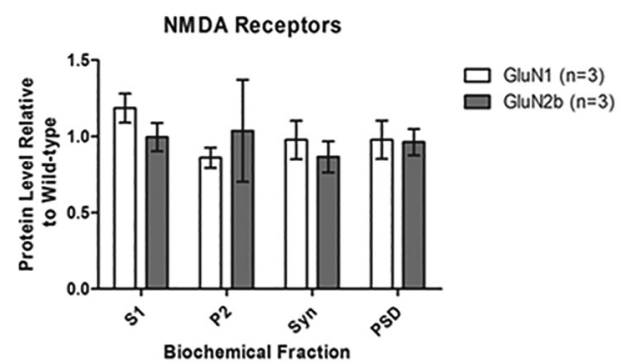

D

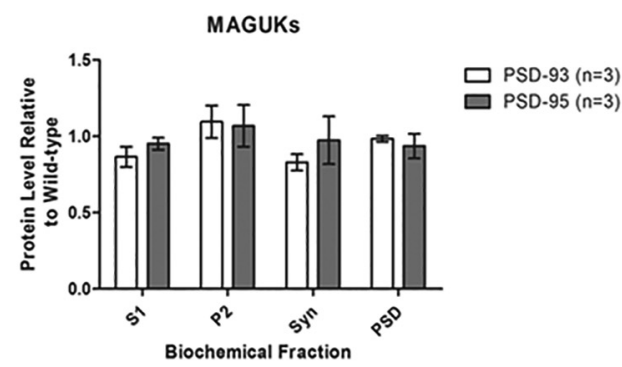

Figure 7. Synapse composition is unaltered in SynDIG1-deficient synapses. $\boldsymbol{A}$, Representative immunoblots of biochemical fractions isolated from WT and SynDIG1 ${ }^{\beta \text {-gal }}$ homozygous mutant P14 mouse brain tissue showing levels of GluA1, GluA2, GluN1, GluN2B, PSD-93, PSD-95, synaptophysin (Synapto), SynDIG1, SynDIG4, and PICK-1 present in the S1-, P2-, Syn-, and PSD-enriched fractions. Loading controls are provided by $\beta$-actin and $\beta$-tubulin immunoreactivity. $\boldsymbol{B}-\boldsymbol{D}$, Graphs depict the ratio of SynDIG1 ${ }^{\beta-g a l}$ homozygous mutant protein relative to WT levels of AMPA receptor subunits (B), NMDA receptor subunits (C), and PSD-93 and PSD-95 $(\boldsymbol{D})$ in the PSD-enriched fractions. Data are the average of three independent biochemical fractionation experiments; each experiment used four to six mouse brains of each genotype. Error bars represent \pm SEM. 
A

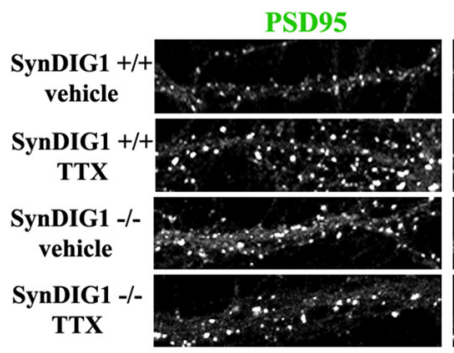

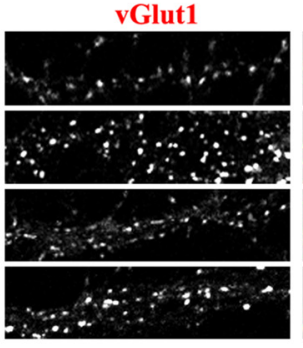

B

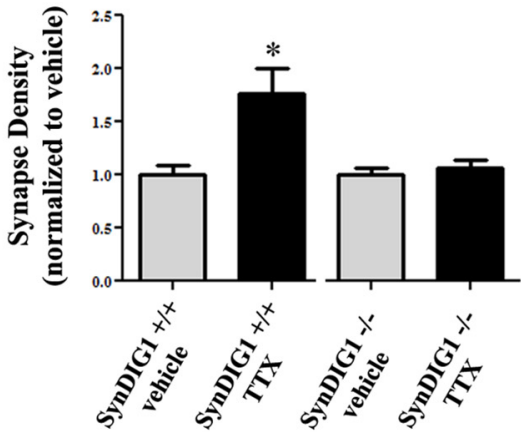

Figure 8. Activity-dependent synapse development was abolished upon the loss of SynDIG1. A, Loss of SynDIG1 inhibits activity-dependent excitatory synapse development. Immunostaining of PSD-95 (green) and presynaptic VGluT1 (red) proteins is shown. Dissociated hippocampal neurons from SynDIG1 $1^{\beta-g a l}$ homozygous mutant $(-/-)$ or WT $(+/+)$ mice were treated with vehicle (DMSO) or TTX $(2 \mu \mathrm{M})$ at 12 DIV, fixed, and stained at 14 DIV. Synapses are defined as the overlap of presynaptic and postsynaptic clusters. Scale bar, $10 \mu \mathrm{m}$. B, Graph depicts the density of PSD-95/VGluT1 colocalized puncta. Normalized values relative to untreated cells are shown for the average of two independent experiments ( $n=20-30$ cells/condition). Error bars represent \pm SEM. $* p<0.05$.

protein product. As such, we did not use that line for any phenotypic analyses and recommend that other researchers instead use the SynDIG1 $1^{\beta \text {-gal }}$ mutant line that we characterized for all subsequent experiments. The secondary function of this line as a reporter also proved quite useful in determining when and where SynDIG1 might be expressed. The SynDIG1 profile in the Allen Mouse Brain Atlas (http://mouse.brain-map.org/experiment/show/ 70723307; http://mouse.brain-map.org/experiment/ show/73931426) matches the expression pattern observed here in the PCL of the cerebellum. Our data further suggest SynDIG1 expression throughout the developing and adult hippocampus and cortex, which is consistent with published in situ hybridization studies (Kalashnikova et al., 2010). The SynDIG1 profile in the Allen Mouse Brain Atlas does not indicate strong SynDIG1 transcription elsewhere in the brain, suggesting that the reporter line is a more sensitive representation of SynDIG1 expression. While the presence of $\beta$-galactosidase shows only promoter activity, our immunoblots from forebrain tissue indicate that SynDIG1 is indeed expressed outside of the cerebellum. Furthermore, the $\beta$-gal expression also matches immunoblot results from a recent publication comparing SynDIG1 expression and the related protein SynDIG4/Prrt1 in rat brain (Kirk et al., 2016).

Together, the results presented here support the conclusion that SynDIG1-deficient excitatory synapses are impaired in their structural and functional properties, and suggest that these synapses are of an immature phenotype based on multiple independent lines of evidence. First, SynDIG ${ }^{\beta-\text { gal }}$ homozygous mutant mice have a significant decrease in PSD length, suggesting a reduction in excitatory synapse maturation. As a synapse matures and strengthens, it will recruit more synaptic proteins, increasing the size of the PSD (Zheng et al., 2011). In support of this interpretation, the number of perforated synapses is decreased significantly in SynDIG ${ }^{\beta-\text { gal }}$ homozygous mutant mice compared with WT animals. Perforated synapses are thought to be indicative of synaptic remodeling during plasticity that occurs normally during development
(Calverley and Jones, 1990) and are more likely to contain AMPA receptors than nonperforated synapses (Ganeshina et al., 2004a,b). Furthermore, there is usually an increase in perforated synapses following LTP induction (Toni et al., 2001). Therefore, a reduction of perforated synapses in SynDIG1 $1^{\beta-g a l}$ homozygous mutant mice also supports the idea that these excitatory synapses are weaker and less mature on average than their WT littermates. The trend toward more synapses in SynDIG ${ }^{\beta-g a l}$ homozygous mutant mice may also be linked to the decreased PSD length and perforated synapse number. It is possible that this trend reflects a compensatory mechanism trying to overcome a lack of mature synapses. Such a compensatory mechanism might also explain the trend toward increased multiple spine synapses observed in SynDIG1 $1^{\beta \text {-gal }}$ homozygous mutant mice compared with WT animals if there is an increase in the drive to form synapses, so more postsynaptic target cells will respond to a presynaptic stimulus. Overall, the loss of SynDIG1 appears to fundamentally alter the structural properties of the normal maturation process of excitatory synapse development.

Second, decreased mEPSC amplitudes in SynDIG1 ${ }^{\beta-\text { gal }}$ homozygous mutant hippocampal slices suggest a decreased responsiveness of postsynaptic cells to glutamate release, another hallmark of smaller, less mature synapses. Moreover, the significant decrease in the interevent interval of mEPSC events in SynDIG1 ${ }^{\beta-\text { gal }}$ homozygous mutant slices indicates that there are more synapses compared with WT mice. These data corroborate the changes observed in the ultrastructure of the excitatory synapses. Namely, there are more yet weaker synapses present in SynDIG $1^{\beta-g a l}$ homozygous mutant mice.

Third, high-frequency glutamatergic stimulation has been shown to increase the volume and response properties of individual spines. This event is correlated with the recruitment of postsynaptic scaffolding molecules and is thought to indicate an increase in spine maturity (Bosch et al., 2014; Colgan and Yasuda, 2014; Meyer et al., 2014). Small spines exhibit increased long-lasting en- 
largement of spine volume upon LTP stimulation in contrast to large spines (Matsuzaki et al., 2004). Large spines are thought to represent "memory" synapses that are stable and fixed, while small spines are "learning" synapses that are substrates for structural remodeling. Indeed, new spines subjected to LTP stimulation are long lasting, indicating that small new spines can mature into persistent larger spines (Hill and Zito, 2013). Small spines from both WT and mutant animals exhibit increased spine volume compared with baseline. In contrast, large spines from mutant neurons showed significantly increased spine volume compared with large spines from WT neurons. Thus, SynDIG1-deficient spines exhibit hyperreactive enlargement upon glutamate uncaging compared with WT spines.

It remains unclear what mechanism is responsible for this excessive increase in volume in SynDIG1 ${ }^{\beta-\text { gal }}$ homozygous mutant mice upon glutamate stimulation. One might expect that hyper-reactive spine enlargement, if long lasting, would result in an increased number of mature synapses. However, we observed the opposite results in our ultrastructure and electrophysiology experiments. We propose that the loss of SynDIG1 impairs the ability of excitatory synapses to mature fully. Spine stimulation via uncaging of glutamate could trigger a maturation response that was primed to be initiated, but fails to do so without SynDIG1. This interpretation might explain why the SynDIG1 $1^{\beta-g a l}$ homozygous mutant spines return to WT levels so soon after glutamate uncaging. Moreover, this "primed yet unable to mature" model also explains why there is a dearth of mature synapses in SynDIG ${ }^{\beta-g a l}$ homozygous mutant mice; without SynDIG1, normal spine maturation is significantly reduced.

How does SynDIG1 influence excitatory synapse maturation? The biochemical fractionation data suggest that the loss of SynDIG1 does not drastically alter the overall composition of excitatory synapses. Preliminary biotinylation studies indicate that surface glutamate receptors are also unchanged (our unpublished observations). However, it remains possible that a yet to be determined upstream or downstream interacting partner of SynDIG1 is drastically altered in SynDIG1 ${ }^{\beta-g a l}$ homozygous mutants. Interestingly, a recent publication (Kaur et al., 2016) demonstrated that palmitoylation of SynDIG1 at two conserved Cys residues in an activity-dependent manner regulates its subcellular localization and function. Therefore, it is tempting to speculate that activity-dependent palmitoylation of SynDIG1 may underlie its role in activitydependent synapse development that is demonstrated here.

In a dissociated culture of rat hippocampal neurons SynDIG1 overexpression leads to an increase in the number and strength of excitatory synapses, and SynDIG1 knockdown results in decreased number and strength of excitatory synapses (Kalashnikova et al., 2010), indicating that the level of SynDIG1 is intimately related to the number and strength of excitatory synapses. We found that a reduction in synapse strength was phenocopied in SynDIG ${ }^{\beta-\text { gal }}$ homozygous mutant hippocampi; however, the effect of genetic removal of SynDIG1 in vivo on syn- apse number is not consistent. It is possible that the SynDIG1-deficient (weaker) synapses that fail to mature are not eliminated, thereby leading to an overall increase in synapse number. This interpretation suggests that synapse formation per se is unaffected in SynDIG1-deficient animals. A recent study (Lovero et al., 2013) in rat hippocampal slice culture concluded that SynDIG1 functions primarily as a synaptogenic factor to regulate excitatory synapse number. This study showed that knockdown of SynDIG1 in a hippocampal slice culture resulted in decreased EPSC without altering AMPA/NMDA ratio or presynaptic release (Lovero et al., 2013). However, in contrast to the in vivo studies presented here as well as to published studies in dissociated rat hippocampal neurons (Kalashnikova et al., 2010), SynDIG1 knockdown in a hippocampal slice culture resulted in decreased mEPSC frequency, with a trend toward decreased mEPSC amplitude (Lovero et al., 2013). The source of the discrepancy could be due to species differences (rat vs mouse hippocampus) or inefficient knockdown of SynDIG1 expression in hippocampal slice culture. It is also possible that the loss of SynDIG1 throughout development (as opposed to acute knockdown of SynDIG1 in slice culture) triggers a compensatory response to increase synapse number due to the overall weakening of SynDIG1-deficient synapses, as discussed above.

In summary, mice with reduced SynDIG1 exhibit deficits in the structure and function of excitatory synapses. Mature synapses are still present, albeit at a significantly reduced number, suggesting that synapses can reach maturity without SynDIG1. However, the overall reduction in the number of mature synapses by multiple criteria suggests that SynDIG1 is important for normal development. The increase in overall synapse number may be due to compensation for this loss of mature synapses or because SynDIG1-deficient synapses fail to be eliminated. Indeed, the increased response to glutamate uncaging demonstrates fundamentally altered excitatory synapse function in SynDIG1 mutant mice. Nevertheless, no candidate glutamate receptor subunits or MAGUKs appear to be altered in the composition of mutant postsynaptic densities, and AMPA/NMDA ratios are unaltered. Therefore, SynDIG1 appears to play an important role in the ability of excitatory synapses to reach or sustain maturity in vivo without gross changes to normal synapse composition.

\section{References}

Bosch M, Castro J, Saneyoshi T, Matsuno H, Sur M, Hayashi Y (2014) Structural and molecular remodeling of dendritic spine substructures during long-term potentiation. Neuron 82:444-459. CrossRef Medline

Bredt DS, Nicoll RA (2003) AMPA Receptor Trafficking at Excitatory Synapses. Neuron 40:361-379. Medline

Calverley RK, Jones DG (1990) Contributions of dendritic spines and perforated synapses to synaptic plasticity. Brain Res Brain Res Rev 15:215-249. Medline

Chen L, Tracy T, Nam Cl (2007) Dynamics of postsynaptic glutamate receptor targeting. Curr Opin Neurobiol 17:53-58. CrossRef Medline 
Colgan LA, Yasuda R (2014) Plasticity of dendritic spines: subcompartmentalization of signaling. Annu Rev Physiol 76:365-385. CrossRef Medline

Díaz E, Ge Y, Yang YH, Loh KC, Serafini TA, Okazaki Y, Hayashizaki Y, Speed TP, Ngai J, Scheiffele P (2002) Molecular analysis of gene expression in the developing pontocerebellar projection system. Neuron 36:417-434. Medline

Elias GM, Nicoll RA (2007) Synaptic trafficking of glutamate receptors by MAGUK scaffolding proteins. Trends Cell Biol 17:343-352. CrossRef Medline

Ganeshina O, Berry RW, Petralia RS, Nicholson DA, Geinisman Y (2004a) Differences in the expression of AMPA and NMDA receptors between axospinous perforated and nonperforated synapses are related to the configuration and size of postsynaptic densities. J Comp Neurol 468:86-95.

Ganeshina O, Berry RW, Petralia RS, Nicholson DA, Geinisman Y (2004b) Synapses with a segmented, completely partitioned postsynaptic density express more AMPA receptors than other axospinous synaptic junctions. Neuroscience 125:615-623.

Haering SC, Tapken D, Pahl S, Hollmann M (2014) Auxiliary subunits: shepherding AMPA receptors to the plasma membrane. Membranes (Basel) 4:469-490. CrossRef Medline

Hansen GM, Markesich DC, Burnett MB, Zhu Q, Dionne KM, Richter LJ, Finnell RH, Sands AT, Zambrowicz BP, Abuin A (2008) Largescale gene trapping in C57BL/6N mouse embryonic stem cells. Genome Res 18:1670-1679. CrossRef Medline

Hill TC, Zito K (2013) LTP-induced long-term stabilization of individual nascent dendritic spines. J Neurosci 33:678-686. CrossRef Medline

Jackson AC, Nicoll RA (2011) The expanding social network of ionotropic glutamate receptors: TARPs and other transmembrane auxiliary subunits. Neuron 70:178-199. CrossRef Medline

Jessell TM, Kandel ER (1993) Synaptic transmission: a bidirectional and self-modifiable form of cell-cell communication. Cell 72:1-30. Medline

Kalashnikova E, Lorca RA, Kaur I, Barisone GA, Li B, Ishimaru T, Trimmer JS, Mohapatra DP, Díaz E (2010) SynDIG1: an activityregulated, AMPA-receptor-interacting transmembrane protein that regulates excitatory synapse development. Neuron 65:80-93. CrossRef Medline

Kaur I, Yarov-Yarovoy V, Kirk LM, Plambeck KE, Barragan EV, Ontiveros ES, Díaz E (2016) Activity-dependent palmitoylation controls SynDIG1 stability, localization, and function. J Neurosci 36:7562-7568. CrossRef Medline
Kirk LM, Ti SW, Bishop HI, Orozco-Llamas M, Pham M, Trimmer JS, Díaz E (2016) Distribution of the SynDIG4/proline-rich transmembrane protein 1 in rat brain. J Comp Neurol 524:2266-2280. CrossRef Medline

Lein ES, Hawrylycz MJ, Ao N, Ayres M, Bensinger A, Bernard A, Boe AF, Boguski MS, Brockway KS, Byrnes EJ, Chen L, Chen L, Chen TM, Chin MC, Chong J, Crook BE, Czaplinska A, Dang CN, Datta S, Dee NR, et al. (2007) Genome-wide atlas of gene expression in the adult mouse brain. Nature 445:168-176. CrossRef Medline

Levy JM, Chen X, Reese TS, Nicoll RA (2015) Synaptic consolidation normalizes AMPAR quantal size following MAGUK loss. Neuron 87:534-548. CrossRef Medline

Lim IA, Hall DD, Hell JW (2002) Selectivity and promiscuity of the first and second PDZ domains of PSD-95 and synapse-associated protein 102. J Biol Chem 277:21697-21711. CrossRef Medline

Lovero KL, Blankenship SM, Shi Y, Nicoll RA (2013) SynDIG1 promotes excitatory synaptogenesis independent of AMPA receptor trafficking and biophysical regulation. PLoS One 8:e66171. CrossRef Medline

Malinow R, Malenka RC (2002) AMPA receptor trafficking and synaptic plasticity. Annu Rev Neurosci 25:103-126. CrossRef Medline

Matsuzaki M, Honkura N, Ellis-Davies GC, Kasai H (2004) Structural basis of long-term potentiation in single dendritic spines. Nature 429:761-766. CrossRef Medline

McAllister AK (2007) Dynamic aspects of CNS synapse formation. Annu Rev Neurosci 30:425-450. CrossRef Medline

Meyer D, Bonhoeffer T, Scheuss V (2014) Balance and stability of synaptic structures during synaptic plasticity. Neuron 82:430-443. CrossRef Medline

Pologruto TA, Sabatini BL, Svoboda K (2003) Scanlmage: flexible software for operating laser scanning microscopes. Biomed Eng Online 17;2:13.Medline

Stoppini L, Buchs PA, Muller D (1991) A simple method for organotypic cultures of nervous tissue. J Neurosci Methods 37:173-182. Medline

Toni N, Buchs PA, Nikonenko I, Povilaitite P, Parisi L, Muller D (2001) Remodeling of synaptic membranes after induction of long-term potentiation. J Neurosci 21:6245-6251. Medline

Waites CL, Craig AM, Garner CC (2005) Mechanisms of vertebrate synaptogenesis. Annu Rev Neurosci 28:251-274. CrossRef Medline

Zheng CY, Seabold GK, Horak M, Petralia RS (2011) MAGUKs, synaptic development, and synaptic plasticity. Neuroscientist 17: 493-512. CrossRef Medline 